ISSN 2075-4701

www.mdpi.com/journal/metals/

Review

\title{
Magnesium-Based Sacrificial Anode Cathodic Protection Coatings (Mg-Rich Primers) for Aluminum Alloys
}

\author{
Shashi S. Pathak, Sharathkumar K. Mendon, Michael D. Blanton and James W. Rawlins * \\ School of Polymers and High Performance Materials, The University of Southern Mississippi, \\ Hattiesburg, MS 39406, USA; E-Mails: shashi.pathak@usm.edu (S.S.P.); \\ sharathkumar.mendon@usm.edu (S.K.M.); michael.blanton@usm.edu (M.D.B.)
}

* Author to whom correspondence should be addressed; E-Mail: james.rawlins@usm.edu; Tel.: +1-601-266-4781; Fax: +1-601-266-5880.

Received: 31 May 2012; in revised form: 6 August 2012 / Accepted: 21 August 2012 /

Published: 14 September 2012

\begin{abstract}
Magnesium is electrochemically the most active metal employed in common structural alloys of iron and aluminum. $\mathrm{Mg}$ is widely used as a sacrificial anode to provide cathodic protection of underground and undersea metallic structures, ships, submarines, bridges, decks, aircraft and ground transportation systems. Following the same principle of utilizing $\mathrm{Mg}$ characteristics in engineering advantages in a decade-long successful $\mathrm{R} \& \mathrm{D}$ effort, $\mathrm{Mg}$ powder is now employed in organic coatings (termed as Mg-rich primers) as a sacrificial anode pigment to protect aerospace grade aluminum alloys against corrosion. Mg-rich primers have performed very well on aluminum alloys when compared against the current chromate standard, but the carcinogenic chromate-based coatings/pretreatments are being widely used by the Department of Defense (DoD) to protect its infrastructure and fleets against corrosion damage. Factors such as reactivity of $\mathrm{Mg}$ particles in the coating matrix during exposure to aggressive corrosion environments, interaction of atmospheric gases with $\mathrm{Mg}$ particles and the impact of $\mathrm{Mg}$ dissolution, increases in $\mathrm{pH}$ and hydrogen gas liberation at coating-metal interface, and primer adhesion need to be considered for further development of Mg-rich primer technology.
\end{abstract}

Keywords: magnesium; sacrificial anode; cathodic protection; Mg-rich primers; anticorrosive coatings; aluminum alloys; corrosion protection 


\section{Introduction}

Magnesium is the sixth most abundant element found in the earth's crust, occurring in over 80 minerals that contain more than $20 \% \mathrm{Mg}$ by weight. Carbonates are the most common form of $\mathrm{Mg}$ in nature. Magnesite $\left[\mathrm{MgCO}_{3}\right]$, dolomite $\left[\mathrm{CaCO}_{3} \cdot \mathrm{MgCO}_{3}\right]$, brucite $\left[\mathrm{Mg}(\mathrm{OH})_{2}\right]$, bishovite $\left[\mathrm{MgCl}_{2} \cdot 6 \mathrm{H}_{2} \mathrm{O}\right]$, carnallite $\left(\mathrm{KCl} \cdot \mathrm{MgCl}_{2} \cdot 6 \mathrm{H}_{2} \mathrm{O}\right)$ and olivine $\left[(\mathrm{MgFe})_{2} \mathrm{SiO}_{4}\right]$ have been considered as raw materials for $\mathrm{Mg}$ metal production [1]. The other major source of $\mathrm{Mg}$ is $\mathrm{MgCl}_{2}$ from seawater.

$\mathrm{Mg}$ is the most electrochemically active metal used in engineering applications (Table 1), and corrodes so readily in some environments that $\mathrm{Mg}$ and $\mathrm{Mg}$ alloys are purposely utilized as sacrificial anodes on steel structures, such as ship hulls and steel pipes. $\mathrm{Mg}$ and $\mathrm{Mg}$ alloys stored at room temperature (STP) or in humid atmospheric conditions develop a compositionally varied surface film, consisting of $\mathrm{Mg}$ oxide, hydroxide, and carbonates. These films are less stable than the passive films formed on metals such as aluminum and stainless steels. The corrosion protection ability of the surface film is highly dependent on environmental conditions, such as humidity, chloride ion concentration, and interaction with atmospheric gases. Corrosion behavior and corrosion protection methods of $\mathrm{Mg}$ and its alloys have been reviewed by several researchers [2-5]. Corrosion resistance of $\mathrm{Mg}$ alloys decreases with increasing relative humidity $(\mathrm{RH})$ and decreasing $\mathrm{pH}$ (below 11.5). Consistently, $\mathrm{Mg}$ resists corrosion in alkaline solutions when the $\mathrm{pH}$ value is above 11.5.

Table 1. Property comparison.

\begin{tabular}{|c|c|c|c|}
\hline Properties of & Magnesium & Aluminum & Iron \\
\hline \multirow{2}{*}{ Crystal structure } & Hep & Fcc & $\mathrm{Bcc}$ \\
\hline & \multicolumn{3}{|c|}{ Ease of fabrication and joining of $\mathrm{Mg}$} \\
\hline \multirow{2}{*}{ Density at $20{ }^{\circ} \mathrm{C}(\mathrm{g} / \mathrm{cc})$} & 1.74 & 2.70 & 7.86 \\
\hline & \multicolumn{3}{|c|}{$\mathrm{Al}$ is $\sim 2.9 \times$ and $\mathrm{Mg}$ is $\sim 4.5 \times$ lighter than $\mathrm{Fe}$} \\
\hline Coefficient of thermal expansion $20-100\left(\times 10^{6} /{ }^{\circ} \mathrm{C}\right)$ & 25.2 & 23.6 & 11.7 \\
\hline Elastic modulus $\left(10^{6} \mathrm{psi}\right)$ & 6.4 & 10 & 30 \\
\hline Melting point $\left({ }^{\circ} \mathrm{C}\right)$ & 650 & 660 & 1536 \\
\hline \multirow{2}{*}{$\begin{array}{l}\text { Standard reduction potential (V vs. Standard } \\
\text { Hydrogen Electrode) }\end{array}$} & -2.37 & -1.66 & -0.447 \\
\hline & \multicolumn{3}{|c|}{$\begin{array}{l}\text { Higher reactivity of } \mathrm{Mg} \text { and } \mathrm{Al} \text { with atmosphere than } \mathrm{Fe} \\
\mathrm{Mg} \text { can act as sacrificial anode }\end{array}$} \\
\hline Cost & $\mathrm{Mg}>\mathrm{Al}>\mathrm{Fe}$ & & \\
\hline
\end{tabular}

Mg's high strength to weight ratio, low density ( $\sim 66 \%$ of aluminum and $25 \%$ of iron), high specific stiffness, high thermal conductivity and electromagnetic shielding properties make it a popular choice in various lightweight applications in aircrafts, automobiles, electronics, and medical implant components. Although $\mathrm{Mg}$ is available commercially with purity above $99.5 \%$, it is rarely used in engineering applications without being alloyed, due to inherent limitations such as low elastic modulus, limited high strength and creep resistance at elevated temperatures, high degree of shrinkage on solidification, high chemical reactivity and limited corrosion resistance. The most commonly used $\mathrm{Mg}$ alloys contain $\mathrm{Al}, \mathrm{Zn}$, and $\mathrm{Mn} ; \mathrm{Al}$ and $\mathrm{Zn}$ are added in ingot form, dissolving readily at normal melt temperature $\left(\sim 700{ }^{\circ} \mathrm{C}\right) . \mathrm{Al}, \mathrm{Zn}$ and $\mathrm{Mn}$ are the major alloying elements in $\mathrm{Mg}$ alloys. Keeping corrosion protection in mind, alloying elements (Al, $\mathrm{Zn}, \mathrm{Mn}$ ) and heavy-metal impurities (Ni, $\mathrm{Fe}, \mathrm{Cu}$ ) of $\mathrm{Mg}$ alloys have to 
be controlled according to the endurance limit. Excess addition of Mn enhances the formation of nobler $\mathrm{Al} \mathrm{Mn}(\mathrm{Fe})$ secondary phase with $\mathrm{Al}$ or $\mathrm{Fe}$ which is detrimental to the corrosion resistance of Mg alloys. Mg alloys such as AZ91D, AZ91E, and AM60B contain very low levels of the heavy metal impurities and offer far better corrosion resistance than ordinary $\mathrm{Mg}$ alloys. The number of applications for $\mathrm{Mg}$ alloys is increasing every year, primarily in the automotive and aerospace sectors.

The established corrosion rate of the secondary phases in $\mathrm{Mg}$ alloys is very low when the $\mathrm{pH}$ is between 4 and 14. Corrosion of $\mathrm{Mg}$ alloys in neutral or alkaline salt solutions is usually initiated as pitting at secondary phase particles. The thickness of the oxide film on secondary phases formed in solution ( $\mathrm{pH}$ 12) was shown to be several times the thickness formed in air and increased with decreasing $\mathrm{pH}$ [6]. The type of processing (ingot, die-cast and extruded $\mathrm{Mg}$ or its alloys) also influenced the nature and severity of the corrosion process due to subtle but important morphology differences. For instance, the corrosion rate of AZ91 ingot and die-cast was higher in acidic solutions ( $\mathrm{pH}$ 1-2) than in neutral and highly alkaline solutions $(\mathrm{pH} 4.5-12)$ [7]. In comparison, extruded $\mathrm{Mg}$ alloy AM60 does not exhibit the same phenomenon in $3.5 \% \mathrm{NaCl}$ solution at different $\mathrm{pH}$ values, however, it undergoes severe pitting corrosion at $\mathrm{pH} 7$ in the absence of pitting (except on the edges) at $\mathrm{pH}$ 12. With the shift towards higher chloride ion concentration, the open circuit corrosion potentials shift to more negative values and the corrosion rates increase at all $\mathrm{pH}$ levels.

$\mathrm{Mg}$ possesses a strong thermodynamic driving force for corrosion and its surface film does not present a very protective kinetic barrier to corrosion [8]. Consequently, $\mathrm{Mg}$ is unsuitable for use singularly in applications involving humid and aqueous environments with $\mathrm{pH}<12$. On the contrary, structural metals such as steel and $\mathrm{Al}$ are cathodic to (more noble in galvanic series than) $\mathrm{Mg}$. In these cases, the undesirably high electrochemical activity of $\mathrm{Mg}$ has been capitalized upon to provide cathodic protection of nobler structural metals/alloys in pipelines, tanks, and marine structures. The premise of cathodic protection is for an electrical circuit to be established as a means to control the corrosion of a structural metal surface by rendering it as the cathode of a galvanic cell. The use of Al, $\mathrm{Zn}, \mathrm{Mg}$, and $\mathrm{Sn} / \mathrm{In}$ to create activated aluminum alloys, as (1) sacrificial anodes and (2) impressed current cathodic protection systems, are established methods to protect steel structures against corrosion $[9,10]$. Mg and its alloys have been used as sacrificial anodes for several decades in cathodic protection of oil and gas pipelines, oil drilling platforms cables, heat exchangers, aircraft, ships, and bridges. In these applications, $\mathrm{Mg}$ acts sacrificially and transfer corrosion activity away from the structural materials to be protected (cathode). The process results in $\mathrm{Mg}$ (anode) dissolution over a given period of time. Figure 1 provides the schematic of sacrificial anode and impressed current protection methods of a pipeline. 
Figure 1. Schematic showing cathodic protection methods using sacrificial anode and impressed current.

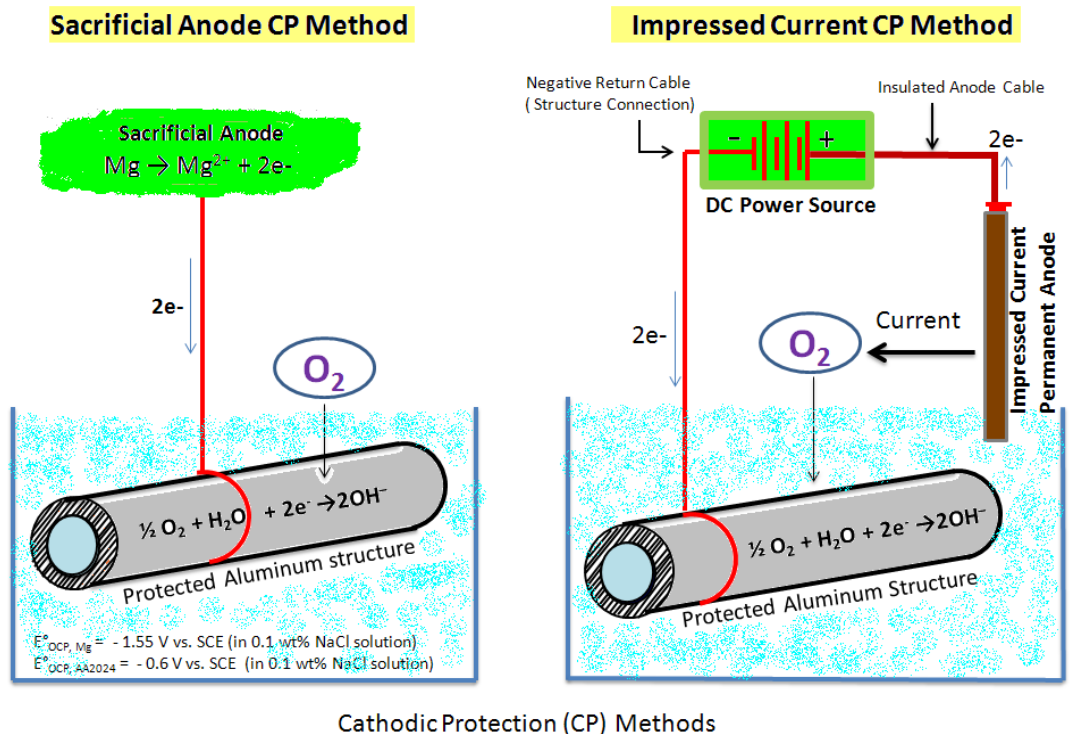

\section{Interaction of Mg and Its Alloys with the Atmosphere}

Corrosion behavior of $\mathrm{Mg}$ and its alloys in the atmosphere differs considerably from their behavior in solution. For example, in the presence of sodium chloride in humid air, the surface of $\mathrm{Mg}$ is rapidly converted and covered by the white, flaky corrosion products of magnesium hydroxide [11]. Chloride ions are known to promote the corrosion of $\mathrm{Mg}$ in aqueous solutions [12]. The anodic reaction ( $\mathrm{Mg}$ dissolution) under a thin electrolyte layer is diminished compared to a bulk electrolyte [13]. Additionally, the main cathodic process in solution is water reduction, while oxygen reduction is the main cathodic reaction during atmospheric corrosion in thin electrolyte layers $[14,15]$. The overall rate of corrosion and nature of corrosion products are strongly influenced by the $\mathrm{RH}$ and chloride ion concentration.

The natural affinity of $\mathrm{Mg}$ and magnesium hydroxide for carbon dioxide has been exploited for $\mathrm{CO}_{2}$ sequestration. Studies investigating the effects of $\mathrm{CO}_{2}$ pressure, temperature, and aqueous solution $\mathrm{pH}$ on rates and mechanisms of magnesium oxide and magnesium hydroxide conversion to magnesium carbonate have established that the combination of high $\mathrm{CO}_{2}$ pressure and high temperature increased the rate of carbonate formation [16,17]. Dissolution of $\mathrm{CO}_{2}$ in the surface electrolyte neutralizes the alkali formed in the cathodic reaction, which initially reduces $\mathrm{pH}$ in the surface electrolyte and increases the dissolution rate of the surface film. The hydroxide ions (formed during the cathodic reaction or dissolved from the film) react with carbonic acid, forming carbonates, which enhance the corrosion performance of $\mathrm{Mg}$ alloys in humid air by forming a physical barrier [18]. The presence of $\mathrm{CO}_{2}$, even at the atmospheric level of $\mathrm{CO}_{2}$, i.e., $350 \mathrm{ppm}$, reduces the corrosion rate by a factor of 3-4 compared that in a $\mathrm{CO}_{2}$-free atmosphere in the presence of $\mathrm{NaCl}\left(0-70 \mathrm{mg} / \mathrm{cm}^{2}\right)$ [19,20]. Lin et al. studied the role of $\mathrm{CO}_{2}$ in the initial stage of atmospheric corrosion of AZ91 magnesium alloy in the presence of $\mathrm{NaCl}$ and concluded that $\mathrm{CO}_{2}$ inhibited $\mathrm{NaCl}$-induced corrosion by generating the slightly soluble hydroxy carbonates that provided a partly protective layer on the surface of the $\mathrm{Mg}$ alloy [21]. In general, magnesium carbonates, such as hydromagnesite $\left[\mathrm{Mg}_{5}\left(\mathrm{CO}_{3}\right)_{4}(\mathrm{OH})_{2} \cdot 4 \mathrm{H}_{2} \mathrm{O}\right)$ and nesquehonite 
$\left(\mathrm{MgCO}_{3} \cdot 3 \mathrm{H}_{2} \mathrm{O}\right)$, have been determined to be the dominant corrosion products on the surface of $\mathrm{Mg}$ and its alloys during $\mathrm{NaCl}$-induced atmospheric corrosion [22]. The protective property of $\mathrm{Mg}$ carbonates on atmospheric corrosion resistance of $\mathrm{Mg}$ alloys has been reported in a number of investigations [23]. In the absence of $\mathrm{CO}_{2}, \mathrm{Mg}(\mathrm{OH})_{2}$ is the dominant corrosion product formed on $\mathrm{Mg}$ surfaces in aqueous solutions and high humidity environments in the presence of $\mathrm{NaCl}$ [24].

Through the proper selection of $\mathrm{Mg}$ alloy components and selective use of coatings and insulation materials, the risk and rates of corrosion can be significantly reduced. Some metallurgical processes, such as rapid solidification and heat treatment, improve mechanical properties and also improve the corrosion resistance of $\mathrm{Mg}$ alloys by refining grain size and distributing the $\beta$ phase along grain boundaries. Carbon inoculation (for $\mathrm{Mg}$ alloys containing $\mathrm{Al}$ and $\mathrm{Mg}-\mathrm{Zr}$ hardeners (for $\mathrm{Mg}$ alloys lacking Al) are commonly used for grain refining/modification.

\section{Magnesium-Rich Primer}

In the early 2000s, following, by analogy the formulation of Zn-rich primer coatings for the protection of steel, researchers at North Dakota State University (NDSU) developed and refined the concept of a Mg-rich primer for cathodic corrosion protection of Al alloys without the use of chromate-based pretreatments or chromate pigments. The research was facilitated by the timely availability of particulate $\mathrm{Mg}$ appropriate for use as a pigment in coatings. While particulate $\mathrm{Mg}$ can pose a fire hazard, the thin layer of $\mathrm{Mg}$ oxide (4\% by weight) on the $\mathrm{Mg}$ particles has been reported to stabilize the bulk $\mathrm{Mg}$ against further oxidation [25]. Moreover, although the natural $\mathrm{Mg}$ oxidation products are basic, they do not yield a $\mathrm{pH}$ high enough to directly corrode and dissolve $\mathrm{Al}$. Since $\mathrm{Mg}$ is more electronegative ( $-2.37 \mathrm{~V}$ vs. SHE) than $\mathrm{Al}(-1.67 \mathrm{~V}$ vs. SHE), the more noble Al substrate in this galvanic couple is cathodically polarized, while the less noble $\mathrm{Mg}$ particles in the coating matrix are anodically dissolved (Figure 2). Sacrificial Mg particles serve as a source of electrical energy. The protective cathodic current generated by contact between $\mathrm{Mg}$ particles in the coating matrix is used in the polarizing cathodic reaction on the Al substrate.

Figure 2. Schematic showing the open circuit potential (OCP) of Mg-rich primer coated AA2024 substrate.

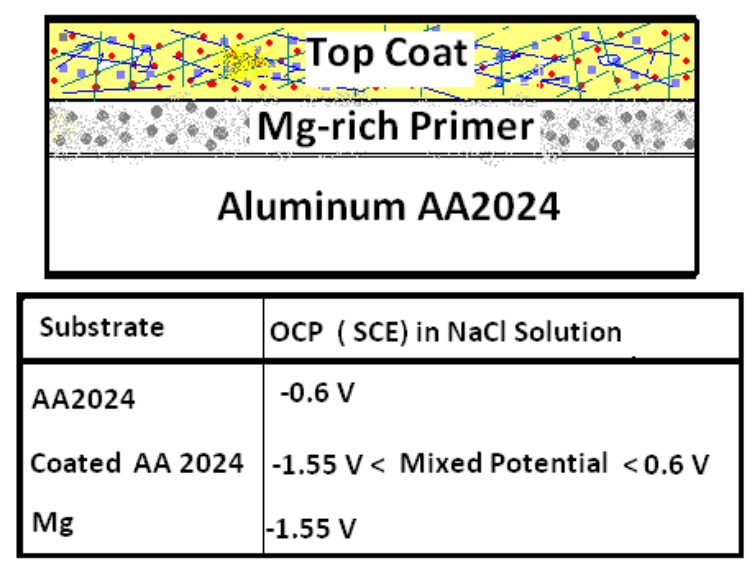

Mg-rich coatings, termed as such because they are formulated to ensure that the $\mathrm{Mg}$ loading exceeds the critical pigment volume concentration (CPVC), contain $\mathrm{Mg}$ particles in physical and 
electrical contact with each other as well as with the substrate. The formulation variables facilitate the flow of cathodic protection current from $\mathrm{Mg}$ particles to the $\mathrm{Al}$ substrate with minimal resistance and protect the underlying substrate from corrosion. Pigment volume concentration (PVC) is defined as the ratio of pigment(s) by volume to the sum volume of pigment(s) and non-volatile binder. The CPVC is the point at which just enough binder exists to cover all the pigment(s) at the densest possible packing and fill the voids between the pigment particles. Beyond the CPVC, therefore, there is insufficient polymer binder to coat the pigment surfaces completely, and the pigment particles are in physical contact with each other. The CPVC is also the point where the dry coating film transitions from a two-phase system of pigment and binder to a three-phase system through the introduction of trapped air voids in the matrix. Mathematically, CPVC can be calculated for a solvent-based coating using Equation 1 [26].

$$
\mathrm{CPVC}=1 /\left(1+\mathrm{OA}_{\mathrm{v}}\right)
$$

where $\mathrm{OA}_{v}$ is the volumetric oil absorption, expressed as milliliter oil/milliliter pigment.

$\mathrm{Mg}$-rich primers have proven in certain applications to be viable or potentially viable alternatives for replacing chromate-based pretreatment and coatings for high strength and light weight aerospace grade Al alloys such as AA2024 T-3 and AA7075 T-6. These phase-separated Al alloys are susceptible to galvanic corrosion due to their highly complex metal-in-metal composite form. Chromates in the form of pigments in primers and as pretreatments for the substrates perform exceptionally well in protecting these alloys from corrosion as they function uniquely as anodic and cathodic inhibitors at very low concentrations in electrolyte solutions, especially with chloride ions that affect $\mathrm{Al}$ substrates [27,28]. However, hexavalent $\mathrm{Cr}$ has been recognized as a human respiratory carcinogen, based on epidemiological and medical evidence accumulated for more than a century [29]. The elimination of toxic $\mathrm{Cr}(\mathrm{VI})$ species in current painting and de-painting operations will have tremendous environmental impact as the waste stream generated through these materials incurs significant disposal costs to the Air Force. It is estimated that the Air Force spends over a billion dollars annually in stripping and repainting aircraft [30]. Furthermore, recent reductions in the $\operatorname{Cr}(\mathrm{VI})$ personnel exposure limit by the Occupational Safety and Health Administration will result in increased compliance costs unless a viable alternative is identified and implemented. A non-chrome/chrome replacement coating system would need to extend the life of existing Al-based assets and facilitate expanded use of economical aluminum alloys in both $\mathrm{DoD}$ and commercial applications [31]. Consequently, extensive research has been conducted in search of alternative technologies, such as anodization [32], sol-gel treatment [33-35], pigmented coatings [36], plasma polymer layers [37], conductive pigments/polymers [38,39], and pigment-based cathodic protection [40].

NDSU sought a patent on their research [41] and subsequently licensed the Mg-rich primer technology to Akzo Nobel Aerospace Coatings who further improved upon the original formulation and resolved the rougher than desirable appearance and usability issues by using smaller Mg particles. Akzo Nobel further optimized the PVC, lowered the volatile organic compound (VOC) levels, and modified the resin system to improve coating flexibility. In 2007, Akzo Nobel produced Aerodur ${ }^{\circledR} 2100$ MgRP that contained green pigment to increase the opacity and facilitate a better contrast ratio for painters to judge wet film thickness [42]. Since that time, Mg-rich coatings have been the topic of research by several researchers and evaluated in many potential applications. Mg-rich primers have proven to be 
quite effective as part of a completely chromate-free coating system comprising a non-film forming surface treatment and an Advanced Performance Coating (APC) grade topcoat, which exhibits excellent corrosion protection of scribed AA2024-T3 panels in both ASTM B 117 and outdoor exposure tests at Daytona Beach, FL [43]. Before discussing the detailed characteristics, stability and performance of corrosion performance of $\mathrm{Mg}$-rich primers, the principle of sacrificial cathodic protection and metallurgical and electrochemical properties of $\mathrm{Mg}$ will be briefly discussed.

\section{Principle of Sacrificial Anode Cathodic Protection}

Cathodic protection is the most widely adopted electrochemical corrosion control technique and is accomplished by applying a direct cathodic protection current (Figure 3) to a structure, effecting a change in potential from the natural corrosion potential $\left(\mathrm{E}_{\mathrm{corr}}\right)$ to a protective potential in the immunity region. Cathodic polarization of the structure controls the kinetics of the electrode processes occurring on the metal-electrolyte interface. The required cathodic current is supplied by means of an impressed current or attachment to a sacrificial anode. The metal structure in contact with an aqueous environment having a near neutral $\mathrm{pH}$ is thereby cathodically protected.

Figure 3. Evans diagram explaining the principle of cathodic protection.

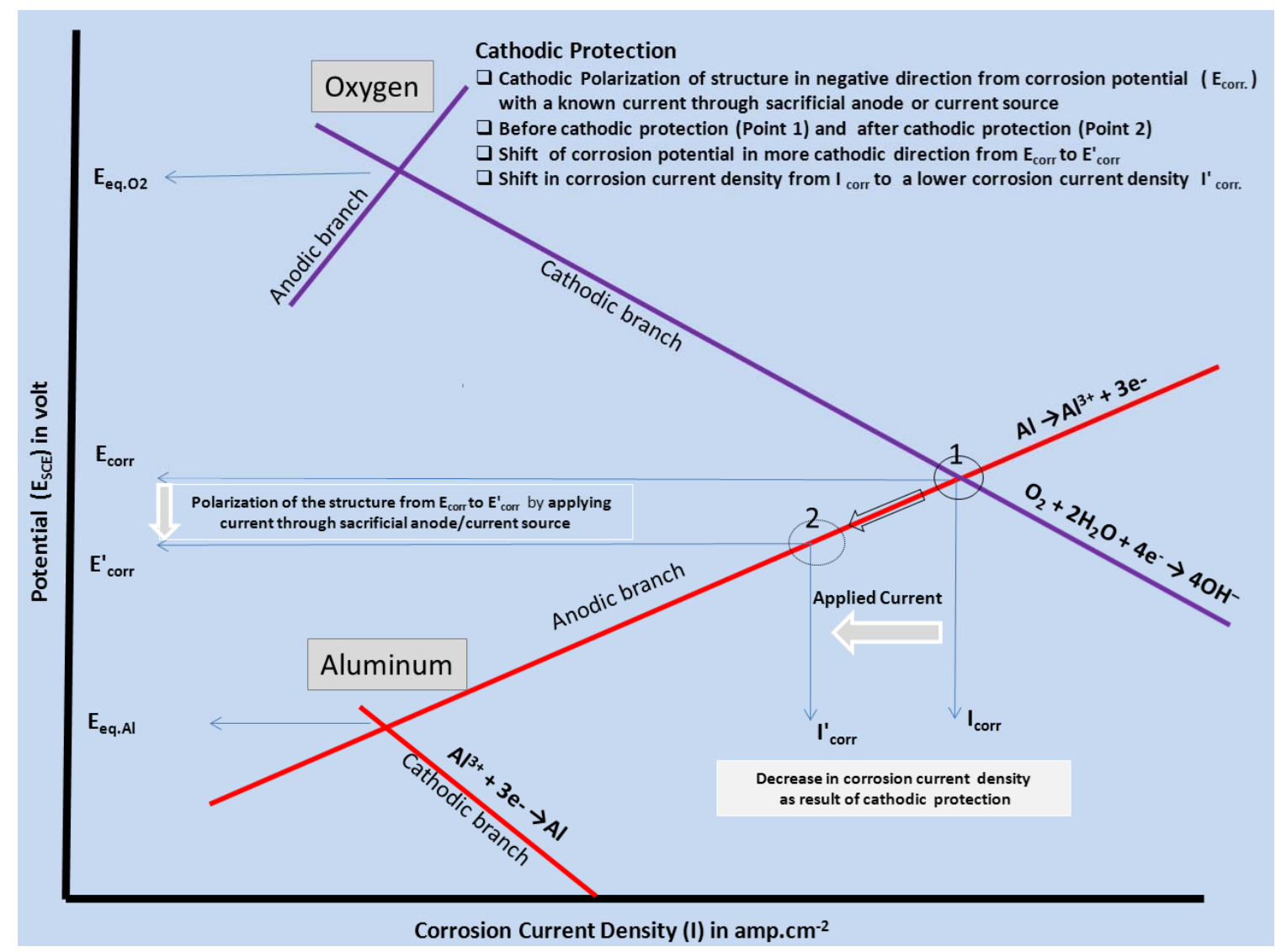

Corrosion involves the active dissolution of metal at anodic sites and reduction of oxygen and/or water at cathodic sites. The severity of corrosion is directly proportional to the magnitude of the difference in potential between the anode and the cathode. Electrons liberated in anodic reactions are consumed in the cathodic reaction. Upon cathodic polarization, the potential of cathodic sites shifts the 
potential of the anodic area to the point at which there is no potential difference between the anode and cathode, thereby minimizing or even eliminating corrosion at the protected substrate. Complete cathodic protection is achieved when the metallic structure becomes the cathode, i.e., more electronegative.

The principle of cathodic protection is well explained by the Wagner-Traud mixed potential theory. According to this theory, any corrosion process can be divided into two or more oxidation and reduction partial reactions with no net accumulation of electric charge during the process. The corrosion reactions occurring in aluminum in an aqueous medium are shown in Equations 2-4:

Anodic reaction:

$$
\mathrm{Al} \rightarrow \mathrm{Al}^{3+}+3 \mathrm{e}^{-} \text {(Aluminum dissolution) }
$$

Cathodic reactions: $\mathrm{O}_{2}+2 \mathrm{H}_{2} \mathrm{O}+4 \mathrm{e}^{-} \rightarrow 4 \mathrm{OH}^{-}$(Oxygen reduction on $\mathrm{Al}$ in neutral or basic solution)

$$
\mathrm{O}_{2}+4 \mathrm{H}^{+}+4 \mathrm{e}^{-} \rightarrow \mathrm{H}_{2} \mathrm{O} \text { (Oxygen reduction on } \mathrm{Al} \text { in acid solutions) }
$$

Corrosion is initiated only when both the anodic and cathodic reactions occur simultaneously. The total rate of oxidation must equal the total rate of reduction in any system. In Figure 3, the relationship between the anodic and cathodic partial corrosion currents for Al has been shown, using mixed potential theory and kinetic equations. As shown in Figure 1, polarization of the cathode in a negative direction from the corrosion potential decreases the corrosion rate. By polarizing the system from $\mathrm{E}_{\text {corr }}$

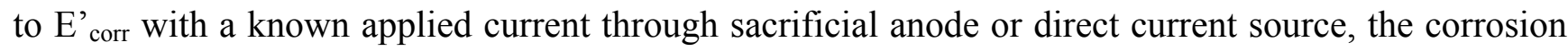
current density decreases from Icorr to I'corr. For complete inhibition of the corrosion processes, it is necessary to polarize the metal to its reversible potential $\mathrm{E}_{\mathrm{Al} / \mathrm{Al}}{ }^{3+}$. The applied current at $\mathrm{E}_{\mathrm{Al} / \mathrm{Al}}{ }^{3+}$ potential is termed as the protection current $[10,44]$. We will limit our discussion here on sacrificial anodes considering only their relevance to $\mathrm{Mg}$-rich primers.

\section{Open Circuit Potential and Potentiodynamic Dynamic Polarization Measurement of Mg-Rich Primer}

Driven by the electrical connection between the Mg-rich primer and the Al substrate, the substrate/primer interface is polarized to the mixed potential of the $\mathrm{Mg}$ particles/Al substrate. The mixed potential of $\mathrm{Al}$ substrate coated with $\mathrm{Mg}$-rich primer is a cathodic potential relative to the open circuit potential (OCP) of the Al substrate itself. OCP and potentiodynamic polarization plots provide an idea of the extent of the cathodic protection versus time during service. An OCP below $\sim-0.9 \mathrm{~V}$ (SCE) for Al $2024 \mathrm{~T}$ provides an indication of the cathodic protection provided by Mg-rich primers [45]. Figure 4 provides a visual summary of the cathodic protection offered by $\mathrm{Mg}$-rich primer to $\mathrm{Al}$ alloy AA2024 T3.

$\mathrm{Mg}$ shifts the potential (cathodically polarizes) of the Al substrate towards more negative potential than the AA2024-T3 substrate. The variation in OCP of AA 2024-T3 (-0.5 VAg/AgCl) and $\mathrm{Mg}(-1.3$ to $-1.5 \mathrm{VAg} / \mathrm{AgCl})$ in $3.5 \mathrm{wt} \% \mathrm{NaCl}$ solution are shown in Figure 4. The $\mathrm{Mg}$-rich primer coated AA2024-T3 aluminum alloy achieved a mix potential (about $-0.9 \mathrm{VAg} / \mathrm{AgCl}$ ) between those of the bare AA2024 T3 substrate and the Mg particles. 
Figure 4. Open circuit potential of Mg-rich primer coated AA2024T3, bare AA2024 T3, and bare $\mathrm{Mg}$ in $3.5 \mathrm{wt} \% \mathrm{NaCl}$ solution.

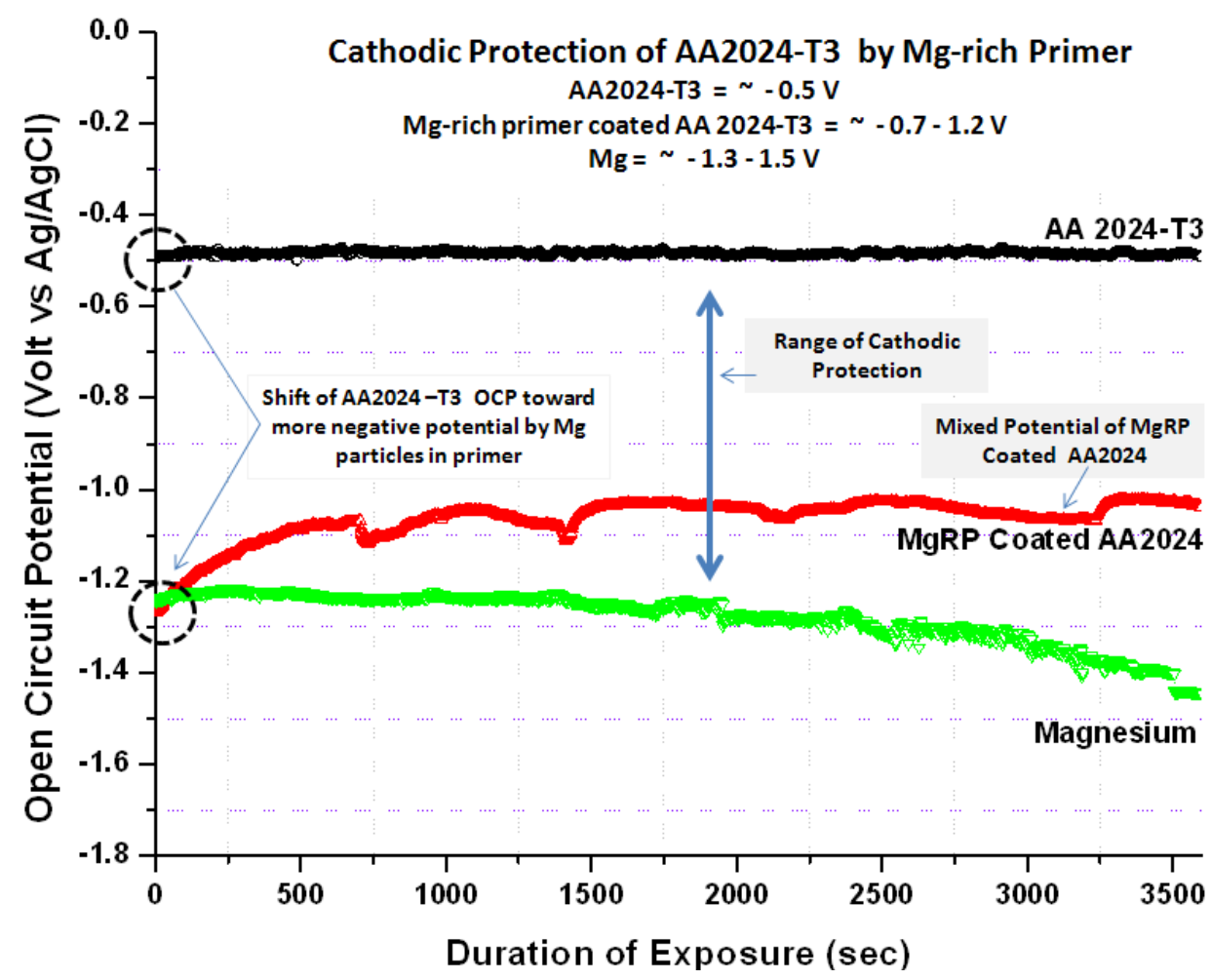

The DC potentiodynamic plot for bare Al alloy AA2024-T3, bare Mg, and Mg-rich primer coated AA2024-T3 (Figure 5) support the concept of mixed potential theory describing the galvanic coupling behavior between the primer and alloy substrate. Potentiodynamic scans show a bare $\mathrm{Mg}$-rich primer coated AA2024-T3 having an OCP in $3.5 \mathrm{wt} \% \mathrm{NaCl}$ solution of about $-1.26 \mathrm{~V}$ vs. $\mathrm{Ag} / \mathrm{AgCl}$ (sat. $\mathrm{AgCl}$ ) while bare AA2024-T351 and bare $\mathrm{Mg}$ exhibit OCP values of about $-0.56 \mathrm{~V}$ and -1.66 vs. $\mathrm{Ag} / \mathrm{AgCl}$ (sat. $\mathrm{AgCl}$ ), respectively. The potentiodynamic plots of coated AA2024-T3 substrate are shifted to lower currents when compared to the bare AA2024-T3.

\section{Performance and Mechanism of Corrosion Protection by Mg-rich Primer}

Mg-rich primers on Al alloys have been shown to perform very well on outdoor exposure at various sites across the US in a variety of applications. The performance of $\mathrm{Mg}$-rich primer depends on various factors such as polymer properties, $\mathrm{Mg}$ PVC, type of $\mathrm{Mg}$ particle (pure $\mathrm{Mg}, \mathrm{Mg}$ alloys or the presence of oxide/hydroxide/carbonate layer on $\mathrm{Mg}$ particles) and the environment. Several electrochemical studies, e.g., electrochemical impedance spectroscopy (EIS), potentiodynamic polarization, scanning vibrating electrode technique (SVET) and scanning electrochemical microscopy (SECM), and OCP studies have been conducted to understand the corrosion protection mechanism offered by Mg-rich primers on aerospace grade Al alloys. These studies most often suggest that cathodic protection was due to uniform corrosion/dissolution of the $\mathrm{Mg}$ particles in coatings matrix. 
Figure 5. DC potentiodynamic polarization measurement of $\mathrm{Mg}$-rich primer coated AA2024T3, bare AA2024 T3 and bare $\mathrm{Mg}$ in $3.5 \mathrm{wt} \% \mathrm{NaCl}$ solution. (scan rate of $0.166 \mathrm{mV} / \mathrm{s}$, polarization range: $\mathrm{OCP}-0.25 \mathrm{mV}$ and $\mathrm{OCP}+0.25 \mathrm{mV}$ ).

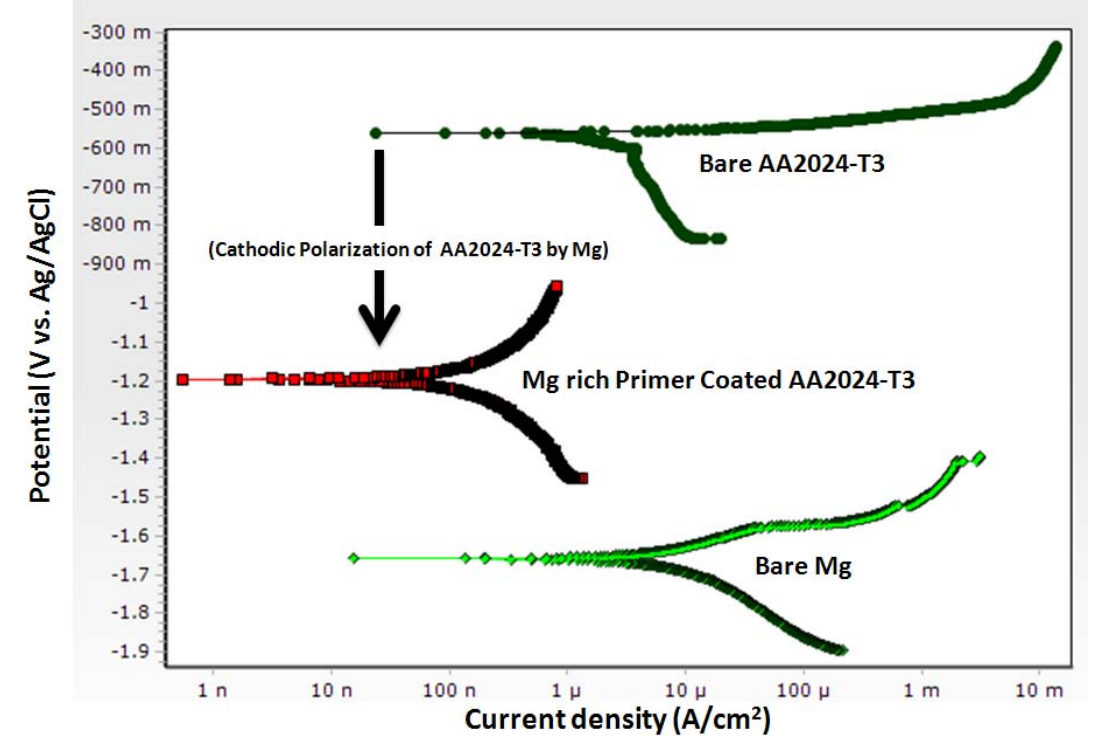

Battocchi et al. employed EIS, OCP and potentiodynamic polarization to study the electrochemical behavior of Mg-rich primer on alloys AA2024 and AA7074, and showed that the Mg-rich primer provides sacrificial protection to the $\mathrm{Al}$ substrate by a two-stage mechanism [46]. In the first stage, $\mathrm{Mg}$ polarizes Al cathodically, shifting its potential below the pitting corrosion potential. The consequence of this polarization can be either the prevention of pit nucleation at the exposed $\mathrm{Al}$ areas, or the inhibition of pit growth for the nucleated pits. During this stage, any defects on the surface will become cathodic, whereas the $\mathrm{Mg}$ particles will be anodic. At the cathodic areas, reduction of hydrogen and possibly dissolved oxygen increases the $\mathrm{pH}$ above the threshold for the precipitation of magnesium oxide. This precipitation leads to the formation of a porous layer that further inhibits corrosion by a barrier mechanism. The typically high dissolution rate of $\mathrm{Mg}$ is significantly decreased by its incorporation in the polymer (a polymeric membrane controlling water, oxygen and electrolytes to varying degrees). In a subsequent paper, the same authors reported the corrosion behavior of the same alloys coated with a magnesium-rich coating, of pure magnesium and of the bare aluminum substrates in $0.1 \% \mathrm{NaCl}$ solution and dilute Harrison's solution (DHS), assessed using electrochemical techniques [47]. The change from $0.1 \% \mathrm{NaCl}$ to dilute Harrison solution (DHS) affected the OCP, the corrosion rates and the equivalent circuits of the systems studied. All along, the $\mathrm{Mg}$ in the coating maintained its protective properties by cathodically polarizing the Al substrates away from their pitting potential. DHS caused pure magnesium to corrode faster due to cathodic de-polarization, which the authors mentioned as being possibly due to the formation of a sulfate ion pair (or complex) of $\mathrm{Mg}$, and also resulted in increased electromotive force for cathodic protection of Al alloys by the Mg-rich primer.

Allahar et al. modeled EIS data of a Mg-rich primer on a gold substrate under immersion in DHS and analyzed it for consistency with Kramers-Kronig relations and applicability for use with a transmission-line model [48]. The data in the frequency range of $1 \mathrm{mHz}$ to $100 \mathrm{kHz}$ were Kramers-Kronig consistent, while the transmission-line model was shown to be applicable for data in 
the $1 \mathrm{mHz}$ to $10 \mathrm{kHz}$ range. In a subsequent paper, Allahar et al. monitored the performance of a Mg-rich primer with a standard US Air Force topcoat on an AA2024 T3 substrate via embedded electrodes placed between the primer and the topcoat, where the coatings were subject to ASTM B117 exposure [49]. EIS and electrochemical noise method experiments indicated that cathodic protection was due to a more uniform corrosion of the $\mathrm{Mg}$ particles, and the loss of cathodic protection resulted in a shift toward a more localized corrosion.

Simões et al. investigated the mechanism of corrosion protection of AA2024 T3 by a Mg-rich coating using SVET and SECM [40,50]. SVET measured the evolution of pit activity with time under sacrificial protection, while SECM allowed indirect sensing of the cathodic activity above the electrodes. The study was complemented by EIS and OCP measurements. The results showed that in the first stage, $\mathrm{Mg}$ acted both by preventing pit nucleation as well as by inhibiting the growth of the already existing ones, whereas at a later stage, the precipitation of a porous layer of magnesium oxide at defective areas was seen to lead to some degree of barrier protection. Cathodic protection provided by the Mg-rich coating was capable of inhibiting pit nucleation by shifting the potential of the system towards the cathodic direction and decreasing the anodic activity at pre-existing pits. Changes in oxygen reduction current indicated that the high corrosion activity of $\mathrm{Mg}$ led to some maintenance of the cathodic reaction on $\mathrm{Mg}$ surface even when it behaved as a sacrificial anode for Al.

$\mathrm{Li}$ et al. investigated the effects of compositional variables associated with formulating a two-component epoxy-amine based Mg-rich primer for protecting alloy AA20224 T3 [51]. An optimized coating composition based on high molecular weight epoxy resin, amide-functional curing agent, epoxy:amine ratio of 1 , and $\mathrm{Mg}$ volume content of $50 \%$ passed over 3,000 hours of ASTM B117 salt spray exposure. Corrosion protection was shown to occur through galvanic coupling between $\mathrm{Mg}$ in the primer and the aluminum substrate. SEM-EDX mapping and electrochemical measurements indicated that $\mathrm{Mg}$ oxidation products may also be playing a role in corrosion protection by increasing the barrier properties over the coating lifetime.

King and Scully attempted to investigate the primary sacrificial and secondary barrier mechanisms of protection afforded to the alloy AA2024-T351 substrate by a Mg-rich primer to estimate the total residual stored $\mathrm{Mg}$ anode capacity and electrically "well-connected" $\mathrm{Mg}$ in the primer as sensed electrochemically, after various environmental exposures [52]. Two possible modes of protection: long-range protection of remote defects and local or short-range $\mathrm{Mg}$ pigment-based protection of local and buried defects were suggested. Both modes of protection were believed to be mediated by the high ionic and electrical resistance of the coating system as a function of PVC and primer/topcoat properties.

While most Mg-rich primers have been formulated with either thermoplastic epoxy resins or thermosetting epoxy-amine systems, Ravindran et al. reported employing a silane-modified glycidyl carbamate binder crosslinked with a polyamide or a polyamine as the continuous phase of their Mg-rich primer [53]. Trimethoxy aminosilane was reacted with hexamethylene diisocyanate-based biuret $(10 \%, 15 \%$ and $20 \%$ silane modification) and the product was reacted with glycidol to synthesize the silane-modified binder. While no corrosion data was presented, the authors reported that the coatings possessed excellent thermal stability as determined via thermogravimetric analysis. As the PVC was increased from $20 \%$ to $40 \%$, the char content increased from $\sim 40 \%$ to $80 \%$ (under nitrogen). The weight gain was attributed to the formation of $\mathrm{Mg}_{3} \mathrm{~N}_{2}$, which decomposes rapidly upon exposure to air to form $\mathrm{MgO} / \mathrm{Mg}(\mathrm{OH})_{2}$. 
Hayes et al. reported that unlike Mg-rich primers, topcoating had negative impact on the corrosion performance of commercial chromate primers. The authors opined that the topcoat may be acting as a vapor/water barrier in limiting the amount of water that penetrated through to the chromate primer, a necessary step which depends on inhibitor solubilization to provide corrosion protection. While the $\mathrm{Mg}$-rich primer also requires contact with water to function, the galvanic corrosion protection provided by the Mg-rich primer does not require the transport of an active corrosion inhibiting species. The authors also suggested that the galvanic protection mechanism could be robust enough where the topcoat does not affect it significantly [54].

$\mathrm{Lu}$ et al. evaluated an epoxy primer with and without $\mathrm{Mg}$ particles on AZ91D alloy using EIS, scanning electron microscopy (SEM) and X-ray diffraction (XRD), and concluded that the Mg-rich primer provided better protection for the alloy than the coating without $\mathrm{Mg}$ particles. Upon immersion in $3 \mathrm{wt} \% \mathrm{NaCl}$ solution for 100 days, $\mathrm{Mg}(\mathrm{OH})_{2}$ was observed to have been formed that precipitates and blocks micropores in the coating, which is beneficial for the coating structure and resistance properties [55].

\section{Unnoticed Factors that Influence the Behavior of Mg-Rich Primers}

Bierwagen concluded that the total system performance of the Mg-rich primer + topcoat was a synergistic blend of the cathodic/sacrificial protection of the primer, the inhibition/thin barrier layer effects of the $\mathrm{MgO} / \mathrm{Mg}(\mathrm{OH})_{2}$ formed as oxidation products of the $\mathrm{Mg}$, the barrier properties of the polymer in the Mg-rich primer, plus the barrier properties of the topcoat [56]. Indeed, panels coated with Mg-rich primers have performed very well on outdoor exposure at various sites across the US. However, it has also been observed that these same Mg-rich primers fail rapidly and exhibit heavy blistering very early on in salt spray tests (ASTM B117), which is still a key MIL-SPEC test in certifying coatings for corrosion protection. This duality in performance could not be explained by the $\mathrm{Mg}$ products mentioned above. The performance contradiction is possibly unique to Mg-rich primers and magnifies the importance of matching mechanisms to outdoor performance in judging and specifying accelerated weathering tests. Failure in salt spray testing may result in a complete dismissal of otherwise viable new technologies for corrosion control materials. Pathak et al. investigated the behavioral dichotomy by exposing Mg-rich primers to salt spray testing and natural weathering and characterizing them at periodic intervals [57]. The coatings were formulated at a PVC of $45 \%$ in a high molecular weight high performance thermoplastic epoxy resin, Eponol ${ }^{\circledR}$, that is supplied as a $35 \%$ solution (by weight) in a blend of methyl ethyl ketone and propylene glycol methyl ether (75:25 by weight), and is reported to have a specific gravity of 0.934 at $25^{\circ} \mathrm{C}$ and $26.6 \%$ volume solids. Eponol was employed as a model polymer in this study as it closely mimics the thermosetting epoxy-amine systems commonly employed in anticorrosive coatings, while affording broader characterization studies because of its thermoplastic nature. The authors reported the presence of a thin and porous magnesium hydroxide layer in Mg-rich primers exposed to salt spray, while a thicker, protective magnesium carbonate layer was detected in the samples when subject to natural weathering. The carbonate film was shown to inhibit both the anodic and the cathodic corrosion processes and does not result in blister formation. Consequently, Mg-rich primers exposed to natural weathering exhibit 
excellent corrosion resistance. However, salt spray conditions are not conducive to facilitate magnesium carbonate formation at a rate versus the rate of dissolution and corrosion.

Strekalov inferred that the amount of adsorbed water present on a magnesium surface at $95 \% \mathrm{RH}$ and $22{ }^{\circ} \mathrm{C}$ corresponds to more than 16 monolayers [58]. At very low concentrations of $\mathrm{CO}_{2}$, this adsorbed water will react with the surface film to form magnesium hydroxide, i.e., brucite, (Equation 5).

$$
\mathrm{Mg}+2 \mathrm{H}_{2} \mathrm{O} \rightarrow \mathrm{Mg}(\mathrm{OH})_{2}+\mathrm{H}_{2}
$$

In the presence of $\mathrm{CO}_{2}$, protolysis of carbonic acid decreases the surface $\mathrm{pH}$ (Equations 6 and 7) [59].

$$
\begin{gathered}
\mathrm{CO}_{2}(\mathrm{aq})+\mathrm{H}_{2} \mathrm{O} \leftrightarrow \mathrm{HCO}_{3}^{-}+\mathrm{H}^{+} \\
\mathrm{HCO}_{3}{ }^{-} \leftrightarrow \mathrm{CO}_{3}{ }^{-2}+\mathrm{H}^{+}
\end{gathered}
$$

Magnesium hydroxide is thermodynamically stable only at low $\mathrm{CO}_{2}$ partial pressure and is converted into magnesite $\left(\mathrm{MgCO}_{3}\right)$ in the presence of atmospheric levels of $\mathrm{CO}_{2}$ (Equation 8) [60-62].

$$
\mathrm{CO}_{2}+\mathrm{Mg}(\mathrm{OH})_{2} \leftrightarrow \mathrm{MgCO}_{3}(\mathrm{~s})+\mathrm{H}_{2} \mathrm{O}
$$

At high RH, magnesite forms a stable hydrated magnesium carbonate, i.e., nesquehonite (Equation 9).

$$
\mathrm{MgCO}_{3}(\mathrm{~s})+3 \mathrm{H}_{2} \mathrm{O} \rightarrow \mathrm{MgCO}_{3} \cdot 3 \mathrm{H}_{2} \mathrm{O}(\mathrm{s})
$$

Equations 5-9 help to explain why $\mathrm{Mg}(\mathrm{OH})_{2}$ was not transformed into magnesium carbonate in $\mathrm{Mg}$-rich primers at the relatively low $\mathrm{CO}_{2}$ content in the salt-spray chamber environment as well as primer film exposed to humid environments in glass jars. The relative proportions of magnesium hydroxide and magnesium carbonate are influenced by $\mathrm{CO}_{2}$ concentration (the salt-spray chamber has less $\mathrm{CO}_{2}$ than field exposure), $\mathrm{CO}_{2}$ solubility (in water/salt water) [63], and chloride concentration [64] all relative to the rates of dissolution and corrosion. Moreover, the solubility of $\mathrm{CO}_{2}$ in water decreases in the presence of sodium chloride $(\mathrm{NaCl}$ concentration is $5 \mathrm{wt} \%$ in salt-spray chamber and $3.5 \mathrm{wt} \%$ in sea water) [65]. The limited availability of $\mathrm{CO}_{2}$ at the surface of the Mg-rich primer and the reduced solubility of $\mathrm{CO}_{2}$ in $5 \mathrm{wt} \%$ salt solution favors rapid dissolution of $\mathrm{Mg}$ in water to form magnesium hydroxide (brucite) with liberation of hydrogen that results in blister formation. Brucite was shown to be only semi-protective due to its plate-like structure. Moreover, the film undergoes compressive rupture due to the higher molar volume of magnesium hydroxide compared to metallic magnesium, resulting in the constant exposure of fresh metal and allowing direct and facile electrolyte ingress [8]. The absence of magnesium carbonate passivation also contributes to poor corrosion protection in Mg-rich primers exposed to salt spray test. Lindström et al. studied the influence of ambient concentrations of $\mathrm{CO}_{2}$ on the atmospheric corrosion of $\mathrm{Mg}$ and reported that in the absence of $\mathrm{CO}_{2}$, a passivating magnesium hydroxide film forms on the $\mathrm{Mg}$ surface that is unable to act as a cathode [20]. In the presence of $\mathrm{CO}_{2}$, the $\mathrm{Mg}$ surface was rendered more passive due to the formation of a thick magnesium hydroxy carbonate film that inhibited both the anodic and the cathodic processes. The authors also reported that immersing $\mathrm{Mg}$ in aqueous $\mathrm{NaCl}$ solution with a limited supply of $\mathrm{CO}_{2}$ resulted in rapid corrosion, which is consistent with the performance of $\mathrm{Mg}$-rich primers in salt spray test.

Pathak et al. reported that SEM micrographs of Mg-rich primer films exposed to salt spray for 30 days exhibited the characteristic "sand rose" [66] or "sunflower" [67] morphology of brucite that was also noted by Bierwagen et al. during electrochemical dissolution of magnesium pigment in water 
and chloride environment (Figure 6). XRD and FTIR data also validated the formation of magnesium hydroxide on Mg-rich primers in the salt-spray chamber. On the other hand, SEM micrographs of free primer films exposed to natural weathering showed the presence of needle-like crystals reported for magnesium carbonate by several authors $[22,68,69]$.

Figure 6. Characterization of $\mathrm{Mg}$ particles used in the formulation of Mg-rich primers.
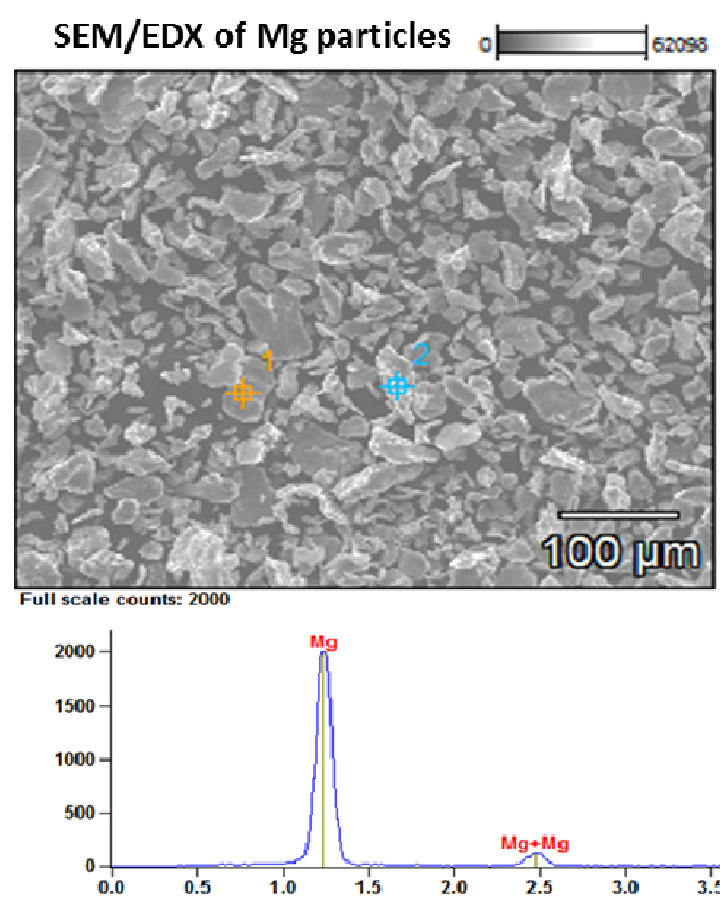

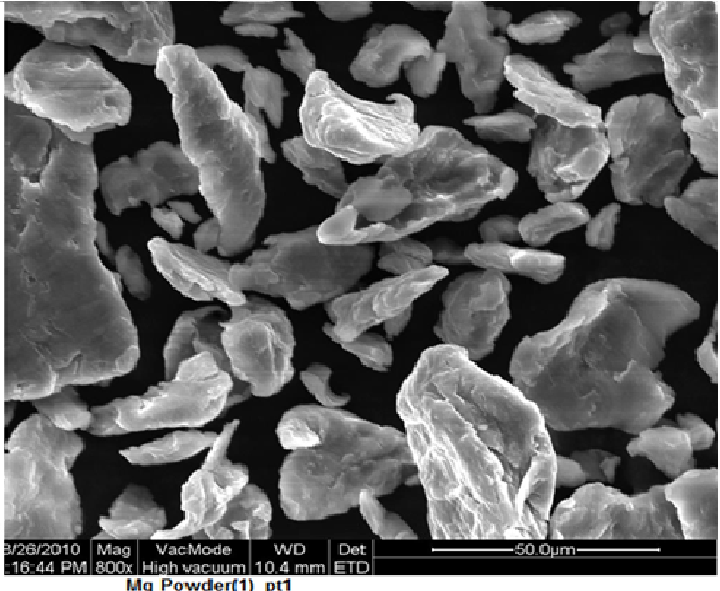

Mg Powder(1) pt1

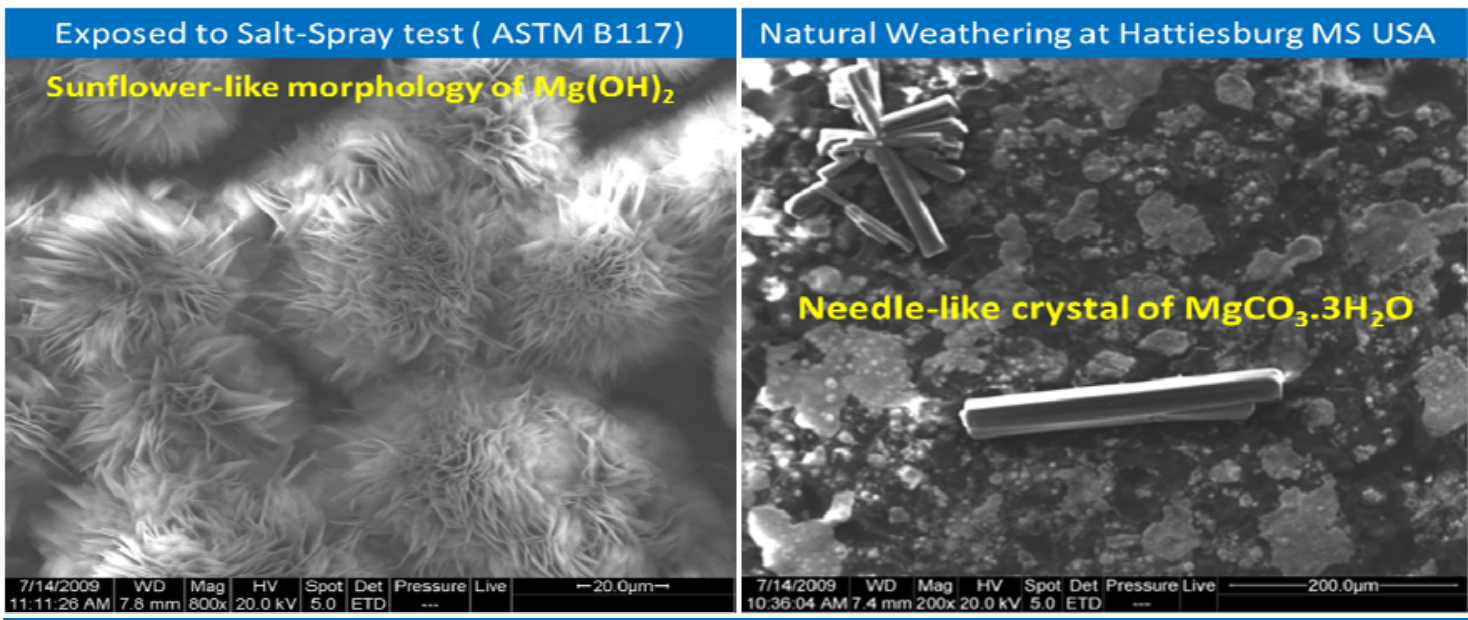

Exposed over the pool of $5 \mathrm{wt} \% \mathrm{NaCl}$ solution in $\mathrm{CO}_{2}$ rich environment

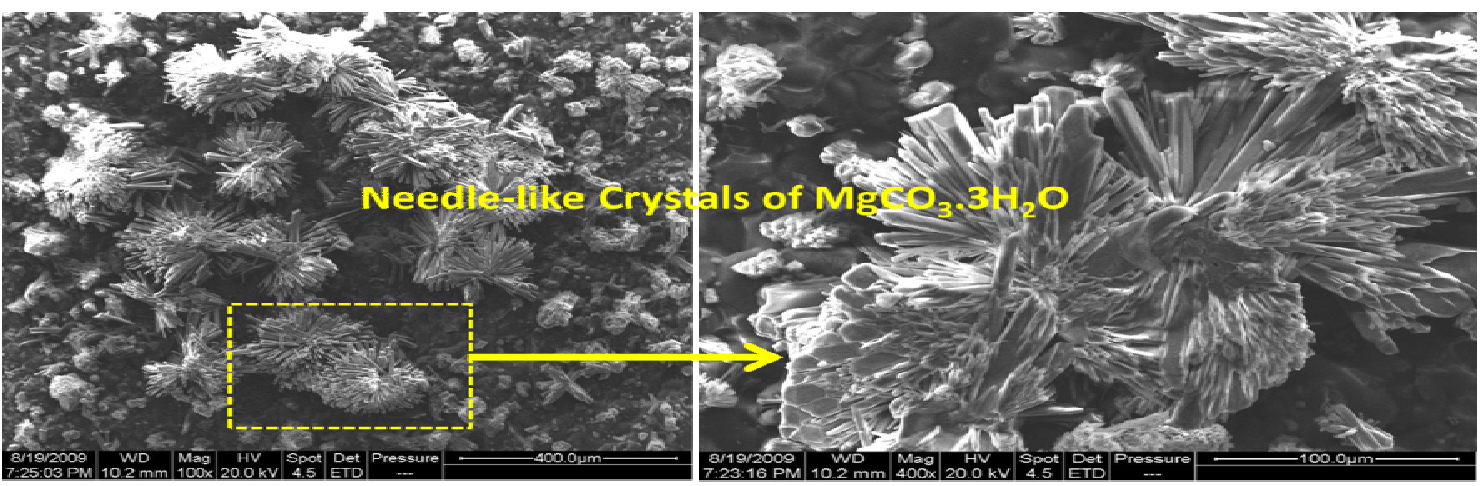


Pathak et al. formulated Mg-rich primers with Eponol, applied them on AA 2024 panels and exposed the coated panels at Daytona, FL and Hawaii (Rain forest) for 6 months [70]. The panels were evaluated via FT-IR (ATR) spectroscopy and compared to similar spectra obtained for Mg particles treated for $3 \mathrm{~h}$ in carbonic acid (Figure 7a). The peaks around $845 \mathrm{~cm}^{-1}$ and in between 1380 and $1530 \mathrm{~cm}^{-1}$ suggest the formation of magnesium carbonates (nesquehonite and/or hydroxy magnesium carbonates). The peak around $3695 \mathrm{~cm}^{-1}$ is due to magnesium hydroxide which appears along with hydroxy magnesium carbonate $\left(3650 \mathrm{~cm}^{-1}\right.$ from $\mathrm{O}-\mathrm{H}$ stretching of water molecule, $845 \mathrm{~cm}^{-1} \mathrm{C}-\mathrm{O}$ anti-symmetric stretching of carbonate, $1380-1530 \mathrm{~cm}^{-1} \mathrm{C}-\mathrm{O}$ symmetric stretching of carbonate) on Daytona and Hawaii exposed Mg-rich primer. The formation of magnesium hydroxide and carbonates in coatings exposed to natural weathering support the explanation behind the behavioral dichotomy of Mg-rich primers.

Figure $7 b$,c summarize the Raman spectra corroborating the FTIR spectra data. Raman spectra (Figure $7 \mathrm{~b}$ ) of $\mathrm{Mg}$ particles treated with carbonic acid solution showing the presence of peak around $1101 \mathrm{~cm}^{-1}$ (Raman shift) corresponding to magnesium carbonate. The Raman spectra of Mg particles and $\mathrm{Mg}$-rich primer (Figure 7c) under various exposure/treatment condition showing the formation of magnesium carbonate naturally with interaction of atmospheric $\mathrm{CO}_{2}$ with $\mathrm{Mg}$ particles in primer and on treated $\mathrm{Mg}$ particles in simulated carbonic acid solution. The peak around $1099 \mathrm{~cm}^{-1}$ (Raman shift) in spectra of treated $\mathrm{Mg}$ particles and $\mathrm{Mg}$-rich primers validate the interaction of $\mathrm{Mg}$ with $\mathrm{CO}_{2}$. An overlapping peak around $1108 \mathrm{~cm}^{-1}$ (Raman shift) also comes from the resin Eponol.

Figure 7. (a) FT-IR (ATR) spectra of Mg-rich primer coated on AA2024 and Mg (untreated and treated) particles; (b) Raman spectra of Mg powder (untreated and treated for $30 \mathrm{~min}$ and $120 \mathrm{~min}$ ); and (c) Raman spectra of Mg particles treated with carbonic acid, Mg-rich primer exposed outdoors, and Eponol coating.

(a)

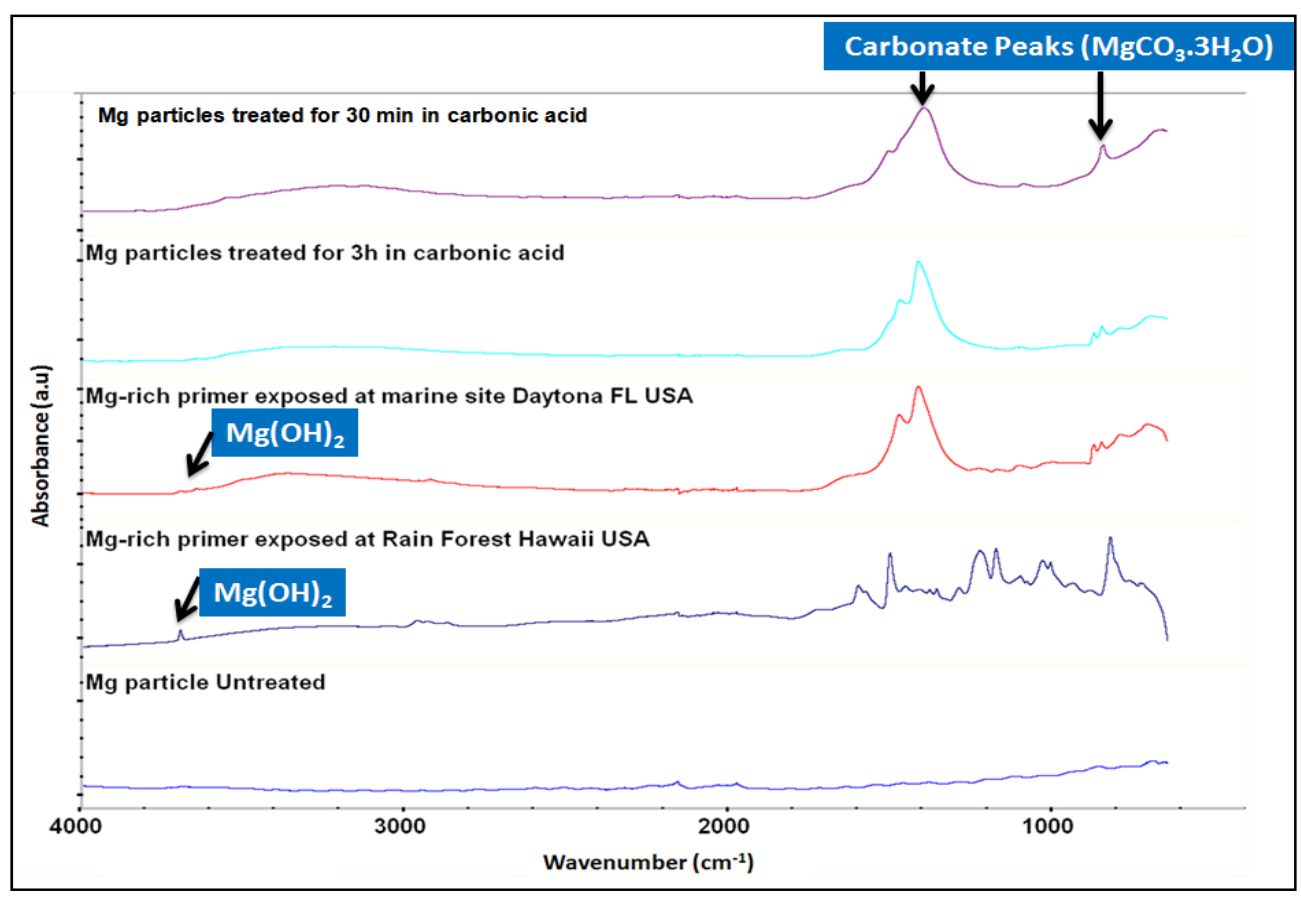


Figure 7. Cont.

(b)
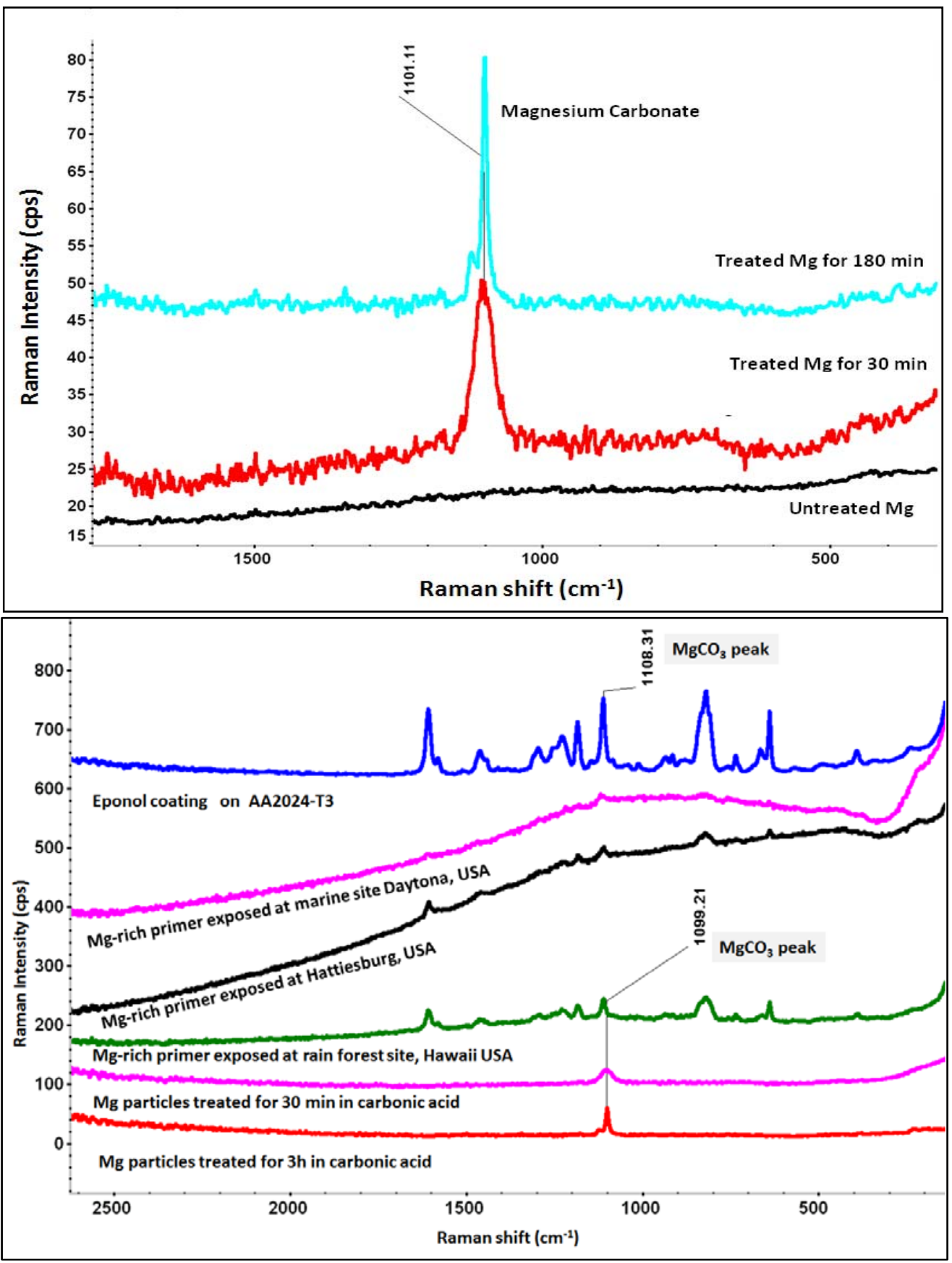

\section{Further Technology Development}

\subsection{Improving Electrochemical Stability by Surface Treatment of Magnesium Particles}

Building upon their earlier work, Pathak et al. treated Mg powder to develop a layer of protective magnesium carbonate on or within $\mathrm{Mg}$ particles at ambient conditions and evaluated the pretreated $\mathrm{Mg}$ in Mg-rich primers [71]. Specifically, $\mathrm{Mg}$ powder was treated with aqueous carbonic acid $\left(\mathrm{CO}_{2}-\mathrm{H}_{2} \mathrm{O}\right.$ solution) for varying lengths of time at ambient conditions and the resulting products were formulated into systematically varying but controllably treated $\mathrm{Mg}$-rich primers with Eponol. The same formulation with the untreated $\mathrm{Mg}$ powder was employed as the control. While nesquehonite was 
identified as a reaction product (Figure 8), magnesium hydroxide formation was not detected in any of the XRD patterns, possibly due to being below the lower detection limit of standard XRD (2\%) and the fact that the hydroxide under these conditions was converted quickly to the carbonate $\mathrm{Mg}$ counterpart [72]. FTIR and FT-Raman analysis indicated that $\mathrm{MgCO}_{3} \cdot 3 \mathrm{H}_{2} \mathrm{O}$ appeared after 20 min of treating $\mathrm{Mg}$ while XRD analysis indicated the presence of $\mathrm{MgCO}_{3} \cdot 3 \mathrm{H}_{2} \mathrm{O}$ after $30 \mathrm{~min}$ of treatment. Extended treatment resulted in a flower-like morphology, possibly due to conversion of nesquehonite to hydroxy magnesium carbonate.

Figure 8. Treatment of $\mathrm{Mg}$ particles prior to coating formulation.

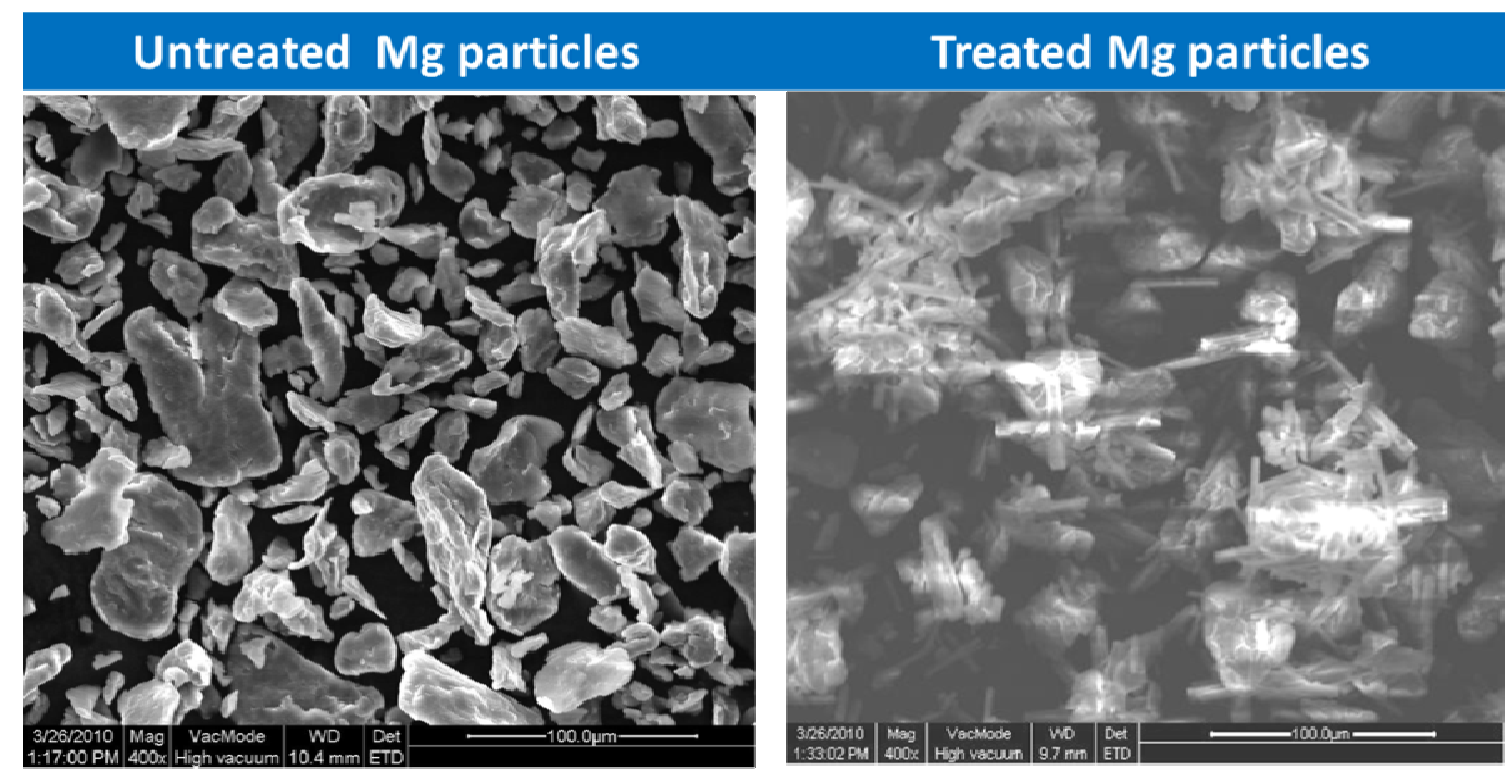

The primer formulated with untreated $\mathrm{Mg}$ powder exhibited severe blistering within $4 \mathrm{~h}$ of being placed in a salt spray chamber (following ASTM B117). However, the primer formulated with $\mathrm{Mg}$ powder treated for $30 \mathrm{~min}$ did not exhibit any detectable or visible changes like blisters even after being in the salt spray chamber for $2160 \mathrm{~h}$. This confirms that coatings formulated with the aqueous carbonic acid-treated $\mathrm{Mg}$ pigment performed similarly to Mg-rich primers exposed to natural weathering where few, if any, failures have been reported in a variety of applications and environmental conditions. The carbonic acid treatment was thus proven to be effective in stabilizing the $\mathrm{Mg}$ particles by reducing its reactivity and rate of dissolution with water and is a more facile approach than other techniques, such as the use of Mg-Al alloy instead of pure Mg [26] or surface treatment of $\mathrm{Mg}$ by organic coatings [73]. Turel et al. established that adding $\mathrm{Mg}$ to an aqueous solution of carbonic acid was the optimal method of generating significant amounts of nesquehonite from $\mathrm{Mg}$ and that a combination of nesquehonite and free $\mathrm{Mg}$ is necessary to protect $\mathrm{Al}$ substrates from corrosion [74].

Maier and Frankel studied the behavior of Mg-rich primers on AA2024 T3 panels and observed that basic or cathodic corrosion of AA2024-T3 is possible for samples in contact with Mg-rich primers [75]. Thin electrolyte layer experiments and cathodic polarization curves in solutions equilibrated with different gases showed that $\mathrm{CO}_{2}$ in high concentration shifts the corrosion potential of $\mathrm{Mg}$ towards cathodic direction and buffers the $\mathrm{pH}$ on the AA2024-T3 surface such that no basic corrosion occurred. However, the amount of atmospheric $\mathrm{CO}_{2}$ was not enough to prevent corrosion in an air-exposed 
AA2024-T3 sample polarized cathodically. The authors also proposed that dissolved $\mathrm{Mg}$ ions could play a role in the protection provided by $\mathrm{Mg}$-rich primers and this influence could be different for exposures in outdoor environments and accelerated weathering environments. Insoluble $\mathrm{Mg}$ compounds formed in the coating pores could function as a protective barrier and such precipitates could form more readily in the moist and cyclic exposure of real environments than in the constant wetness of a salt spray chamber.

\subsection{Use of Mg Alloys instead of Pure Mg Particles}

$\mathrm{Xu}$ et al. investigated three different Mg alloys (AM60, AZ91B, and LNR91 with Al content of 5\%, $8.5 \%$ and $50 \%$, respectively) as pigments in an epoxy-polyamide system at various PVC values [76]. The alloy pigments were characterized by large particle sizes (>60 microns) and varying shapes, e.g., AM60 has a plate-like shape with a smooth edge, AZ91B has a chip-like shape, and LNR91 has a cubic-like shape with a sharp edge. EIS and SEM studies indicated that the Mg alloy pigments provided sacrificial protection to the Al alloy substrates and that precipitates formed from oxidation of the $\mathrm{Mg}$ alloy particles were similar to the ones found in pure Mg-rich primers. In a subsequent paper, Bierwagen et al. discussed the surface compositions of two Mg alloy pigments, AM60 and AZ91B, and how coatings formulated with them changed in Prohesion chamber (where DHS is employed as the spray solution) studies [77]. For both these alloy pigments, XPS depth profile revealed a three layer structure (from outside to inside) as (a) $\mathrm{MgCO}_{3}$; (b) $\mathrm{MgCO}_{3} ; \mathrm{MgO}$ and metallic $\mathrm{Mg}, \mathrm{Al}$ mixture; and (c) metallic core of $\mathrm{Mg}$ and $\mathrm{Al}$. In Prohesion chamber studies with AM60, the nature of the corrosion products changed as a function of the PVC. Below the critical PVC (CPVC), the major corrosion products were identified as $\mathrm{MgAl}_{2} \mathrm{O}_{4}, \mathrm{Al}_{2} \mathrm{O}_{3}$, and $\mathrm{AlOOH}$. Above CPVC, the major corrosion product changed to $\mathrm{MgCO}_{3}$. Below CPVC, the DHS acts primarily at the coating surface where it oxidizes the $\mathrm{Mg}$ first to $\mathrm{Mg}(\mathrm{OH})_{2}$ and then the $\mathrm{Al}$ to $\mathrm{Al}(\mathrm{OH})_{3}$ at higher $\mathrm{pH}$. In the drying cycle, these products form $\mathrm{MgAl}_{2} \mathrm{O}_{4}, \mathrm{Al}_{2} \mathrm{O}_{3}$, and $\mathrm{AlOOH}$. Above the $\mathrm{CPVC}$, the DHS is able to penetrate into the coating where it neutralizes the area around the $\mathrm{Mg}$ particles as it is oxidized and maintains the $\mathrm{pH}$ low enough to prevent the oxidation of $\mathrm{Al}$. The coating porosity also facilitates the penetration of $\mathrm{CO}_{2}$ into the coating matrix, which converts the $\mathrm{Mg}(\mathrm{OH})_{2}$ to $\mathrm{MgCO}_{3}$.

\subsection{Additional Corrosion Inhibitive Components to Improve Mg-rich Performance}

Addition of small amounts of cerium oxide ( $0.5 \%$ by weight) to a Mg-rich primer was shown to significantly improve the protection performance of a Mg-rich primer on AZ91D magnesium alloy [78]. While the ceria particles did not change the protection mechanisms of the Mg-rich primer on AZ91D magnesium alloy, the authors claimed that the electrochemical activity of the $\mathrm{Mg}$ particles increased the service life of the Mg-rich primer. Apart from providing a barrier effect, ceria particles increased the corrosion potential and decreased the current density of the AZ91D alloy, which is beneficial for cathodic protection of the $\mathrm{Mg}$ particles. Lu et al. reported improved adhesion and better corrosion protection when the surface of AZ91D magnesium alloy substrates were coated with $\gamma$-glycidoxy propyl trimethoxy silane, due to the formation of $\mathrm{Si}-\mathrm{O}-\mathrm{Mg}$ covalent bonds between the silane film and the substrate and Si-O-Si bonds within the silane film, each shifting the water and oxygen permeability drastically [79]. 


\section{Conclusion}

Mg-rich primers represent the first commercially viable, high performance (in corrosion control terms) and non-toxic alternative to the use of carcinogenic $\mathrm{Cr}(\mathrm{VI})$ pretreatments and pigments for preventing corrosion on metal substrates, especially on aluminum alloys used in the aircraft industry. Mg-rich primer technology has advanced drastically since its conception with many of the limitations having been overcome via thorough understanding of the mechanisms by which $\mathrm{Mg}$ particles afford their corrosion protection abilities. Yet, incremental and important improvements are still occurring in Mg-rich primer technology, both in the academic and industrial laboratories and applications, and it is possible that it will not be too long before these primers become the standard against which all other anti-corrosive primer alternatives will be evaluated.

\section{Acknowledgments}

The authors gratefully acknowledge the financial support of Mandaree Enterprise Corporation (FA8501-06-D-0001), Engineer Research and Development Center (ERDC W9132T-09-2-0019) and The United States Air Force (FA7000-10-2-0014) through funding by the Department of Defense and collaborative efforts for Corrosion Prevention and Understanding via the Technical Corrosion Collaboration working group comprising The University of Virginia, The University of Hawaii, The Ohio State University, the Air Force Academy, The University of Akron, The University of Southern Mississippi, the Air Force Institute of Technology, the Naval Postgraduate School, the US Naval Academy, and Nippon Paper Chemicals Co., Ltd.

\section{Conflict of Interest}

The authors declare no conflict of interest.

\section{References}

1. Simandl, G.J.; Schultes, H.; Simandl, J.; Paradis, S. Magnesium-raw materials, metal extraction and economics - Global picture. In Digging Deeper, Proceedings of the Ninth Biennial SGA Meeting; Irish Association for Economic Geology: Dublin, UK, 2007; pp. 827-831.

2. Guo, K.W. A review of magnesium/magnesium alloys corrosion. Recent Pat. Corros. Sci. 2011, 1, 72-90.

3. Wu, C.-Y.; Zhang, J. State-of-art on corrosion and protection of magnesium alloys based on patent literatures. Trans. Nonferrous Met. Soc. China 2011, 21, 892-902.

4. Gray, J.E.; Luan, B. Protective coatings on magnesium and its alloys-A critical review. J. Alloy Compd. 2002, 336, 88-113.

5. Zeng, R.-C.; Zhang, J.; Huang, W.-J.; Dietzel, W.; Kainer, K.U.; Blawert, C.; Ke, W. Review of studies on corrosion of magnesium alloys. Trans. Nonferrous Met. Soc. China 2006, 16, 763-771.

6. Song, G.; Atrens, A. Corrosion mechanisms of magnesium alloys. Adv. Eng. Mater. 1999, 1, 11-33.

7. Ambat, R.; Aung, N.N.; Zhou, W. Evaluation of microstructural effects on corrosion behavior of AZ91D magnesium alloy. Corros. Sci. 2000, 42, 1433-1455. 
8. Shaw, B.A.; Wolfe, R.C. Corrosion of Magnesium and Magnesium-Base Alloys. In ASM Handbook, Corrosion: Materials; Cramer, S.D., Covino, B.S., Jr., Eds.; ASM International: Russell Township, OH, USA, 2005; Volume 13B, pp. 205-227.

9. Gurrappa, I. Cathodic protection of cooling water systems and selection of appropriate materials. J. Mater. Process. Technol. 2005, 166, 256-267.

10. Popov, B.N.; Kumaraguru, S.P. Cathodic Protection of Pipelines. In Handbook of Environmental Degradation of Materials; Myer, K., Ed.; William Andrew Publishing: Norwich, NY, USA, 2005; Chapter 24, pp. 503-521.

11. Lindström, R. Atmospheric Corrosion of Magnesium alloys Influence of Microstructure and Environment. Ph.D. Thesis, Göteborg University, Göteborg, Sweden, 2007.

12. Loose, W.S. Corrosion and Protection of Magnesium. In Metals Handbook; Pidgeon, L.M., Mathes, J.C., Woldmen. N.E., Eds.; ASM International: Russell Township, OH, USA, 1946; pp. 173-260.

13. Rozenfeld, I.L. Atmospheric Corrosion of Metals; National Association of Corrosion Engineers: Houston, TX, USA, 1972.

14. Tomashov, N.D. Theory and Protection of Metals: The Science of Corrosion; The Macmillan Company: London, UK, 1966; pp. 367-398.

15. Jönsson, M.; Persson, D.; Leygraf, C. Atmospheric corrosion of field-exposed magnesium alloy AZ91D. Corros. Sci. 2008, 50, 1406-1413.

16. Prigiobbe, V.; Hänchen, M.; Werner, M.; Baciocchi, R.; Mazzotti, M. Mineral carbonation process for $\mathrm{CO}_{2}$ sequestration. Energy Proced. 2009, 1, 4885-4890.

17. Bruant, R.G., Jr.; Giammar, D.E.; Myneni, S.C.B.; Peters, C.A. Effect of pressure, temperature, and aqueous carbon dioxide concentration on mineral weathering as applied to geologic storage of carbon dioxide. In Proceedings of the 6th International Conference on Greenhouse Gas Control Technologies, Kyoto, Japan, 1-4 October 2002; pp. 1609-1612.

18. Feliu, S., Jr.; Pardo, A.; Merino, M.C.; Coy, A.E.; Viejo, F.; Arrabal, R. Correlation between the surface chemistry and the atmospheric corrosion of AZ31, AZ80 and AZ91D magnesium alloys. Appl. Surf. Sci. 2009, 255, 4102-4108.

19. Lindström, R.; Johansson, L.G.; Svensson, J.E. The influence of $\mathrm{NaCl}$ and $\mathrm{CO}_{2}$ on the atmospheric corrosion of magnesium alloy AZ91. Mater. Corros. 2003, 54, 587-594.

20. Lindström, R.; Johansson, L.G.; Thompson, G.E.; Skeldon, P.; Svensson, J.E. Corrosion of magnesium in humid air. Corros. Sci. 2004, 46, 1141-1158.

21. Lin, C.; Li, X. Role of $\mathrm{CO}_{2}$ in the initial stage of atmospheric corrosion of AZ91 magnesium alloy in the presence of $\mathrm{NaCl}$. Rare Met. 2006, 25, 190-196.

22. Hao, Z.; Du, F. Synthesis of basic magnesium carbonate microrods with a "house of cards" surface structure using rod-like particle template. J. Phys. Chem. Solids 2009, 70, 401-404.

23. Blücher, D.B.; Svensson, J.-E.; Johansson, L.-G.; Rohwerder, M.; Stratmann, M. Scanning Kelvin probe force microscopy: A useful tool for studying atmospheric corrosion of MgAl alloys in situ. J. Electrochem. Soc. 2004, 151, B621-B626.

24. Lindström, R.; Svensson, J.-E.; Johansson, L.-G. The influence of carbon dioxide on the atmospheric corrosion of some magnesium alloys in the presence of $\mathrm{NaCl}$. J. Electrochem. Soc. 2002, 149, B103-B107. 
25. Nanna, M.E.; Bierwagen, G.P. Mg-rich coatings: A new paradigm for Cr-free corrosion protection of Al aerospace alloys. J. Coat. Technol. Res. 2004, 1, 69-80.

26. Glancy, C.W. Oil Absorption of Pigments. In Paint and Coating Testing Manual: 15th Edition of the Gardner-Sward Handbook; Joseph, K., Ed.; ASTM International: West Conshohocken, PA, USA, 2012; Chapter 29, pp. 304-305.

27. Bierwagen, G.P.; Brown, R.; Battocchi, D.; Hayes, S. Active metal-based corrosion protective coating systems for aircraft requiring no-chromate pretreatment. Prog. Org. Coat. 2010, 68, 48-61.

28. Osborne, J.H.; Blohowiak, K.Y.; Taylor, S.R.; Hunter, C.; Bierwagen, G.P.; Carslon, B.; Bernard, D.; Donley, M.S. Testing and evaluation of non-chromated coating systems for aerospace applications. Prog. Org. Coat. 2001, 41, 217-225.

29. Covino, J.J.; Sugden, K.D. Genotoxicity of chromate. Adv. Mol. Toxic. 2008, 2, 1-24.

30. Morris, E.; Ray, C.; Albers, R.; McLaughlin, J.; Bean, S.; DeAntoni, A.; Patel, R. Using chrome-free primer technology to develop a chrome-free pretreatment. In Proceedings of the 2007 Tri-Service Corrosion Conference, Denver, CO, USA, 3-6 December 2007; Available online: https://www.corrdefense.org/technical\%20papers/using\%20chrome-free\%20primer\%20technol ogy\%20to\%20develop\%20a\%20chrome-free\%20pretreatment.pdf (accessed on 30 May 2012).

31. Joint DoD Demonstration and Validation of Magnesium Rich Primer Coating Technology. Available online: http://www.serdp.org/Program-Areas/Weapons-Systems-and-Platforms/SurfaceEngineering-and-Structural-Materials/Coatings/WP-200731 (accessed on 30 April 2012).

32. Twite, R.L.; Bierwagen, G.P. Review of alternatives to chromate for corrosion protection of aluminum aerospace alloys. Prog. Org. Coat. 1998, 33, 91-100.

33. Pathak, S.S.; Khanna, A.S. Synthesis and performance evaluation of environmentally compliant epoxysilane coatings for aluminum alloy. Prog. Org. Coat. 2008, 62, 409-416.

34. Pathak, S.S.; Khanna, A.S. Investigation of anti-corrosion behavior of waterborne organosilane-polyester coatings for AA6011 aluminum alloy. Prog. Org. Coat. 2009, 65, 288-294.

35. Pathak, S.S.; Sharma, A.; Khanna, A.S. Value addition to waterborne polyurethane resin by silicone modification for developing high performance coating on aluminum alloy. Prog. Org. Coat. 2009, 65, 206-216.

36. Hamdy, A.S. Enhancing corrosion resistance of aluminum composites in $3.5 \% \mathrm{NaCl}$ using pigmented epoxy fluoropolymer. Prog. Org. Coat. 2006, 55, 218-224.

37. Yasuda, H.K.; Reddy, C.M.; Yu, Q.S.; Deffeyes, J.; Bierwagen, G.P.; He, L. Effect of scribing on corrosion test results. Corrosion 2001, 57, 29-34.

38. He, J.; Gelling, V.J.; Tallman, D.E.; Bierwagen, G.P.; Wallace, G.G. Conducting polymers and corrosion. III. A scanning vibrating electrode study of poly(3-octyl pyrrole) on steel and aluminum. J. Electrochem. Soc. 2000, 147, 3667-3672.

39. Tallman, D.E.; Pae, Y.; Bierwagen, G.P. Conducting polymers and corrosion. 2. Polyaniline on aluminum alloys. Corrosion 2000, 56, 401-410.

40. Simões, A.; Battocchi, D.; Tallman, D.; Bierwagen, G.P. Assessment of the corrosion protection of aluminium substrates by a Mg-rich primer: EIS, SVET and SECM study. Prog. Org. Coat. 2008, 63, 260-266. 
41. Bierwagen, G.P.; Nanna, M.E.; Battocchi, D. Magnesium Rich Coatings and Coating Systems. U.S. Patent 20,070,128,351, 7 October 2004.

42. Price, C.J.; Johnson, J. Performance Evaluation of a Magnesium-Rich Primer for Chrome-Free Aerospace Coating Systems. Available online: http://symposiumarchive.serdp-estcp.org/ symposium2008/posters/upload/w189-joseph.pdf (accessed on 30 May 2012).

43. Johnson, J.A. Magnesium rich primer for chrome free protection of aluminum alloys. In Proceedings of the Tri-Service Corrosion Conference 2007, Denver, CO, USA, 3-7 December 2007.

44. Ahmad, Z. Cathodic Protection. In Principles of Corrosion Engineering and Corrosion Control; Butterworth-Heinemann: Oxford, UK, 2006; pp. 271-351.

45. Bierwagen, G.; Battocchi, D.; Simoes, A.; Stamness, A.; Tallman, D. The use of multiple electrochemical techniques to characterize Mg-rich primers for Al alloys. Prog. Org. Coat. 2007, 59, 172-178.

46. Battocchi, D.; Simões, A.M.; Tallman, D.E.; Bierwagen, G.P. Electrochemical behaviour of a Mg-rich primer in the protection of Al alloys. Corros. Sci. 2006, 48, 1292-1306.

47. Battocchi, D.; Simões, A.M.; Tallman, D.E.; Bierwagen, G.P. Comparison of testing solutions on the protection of Al-alloys using a Mg-rich primer. Corros. Sci. 2006, 48, 2226-2240.

48. Allahar, K.N.; Battocchi, D.; Orazem, M.E.; Bierwagen, G.P.; Tallman, D.E. Modeling of electrochemical impedance data of a magnesium-rich primer. J. Electrochem. Soc. 2008, 155, E143-E149.

49. Allahar, K.N.; Wang, D.; Battocchi, D.; Bierwagen, G.P.; Balbyshev, S. Real-time monitoring of a United States air force topcoat/Mg-rich primer system in ASTM B117 exposure by embedded electrodes. Corrosion 2010, 66, 075003:1-075003:11.

50. Simões, A.M.; Battocchi, D.; Tallman, D.E.; Bierwagen, G.P. SVET and SECM imaging of cathodic protection of aluminium by a Mg-rich coating. Corros. Sci. 2007, 49, 3838-3849.

51. Li, J.; He, J.; Chisholm, B.J.; Stafslien, M.; Battocchi, D.; Bierwagen, G.P. An investigation of the effects of polymer binder compositional variables on the corrosion control of aluminum alloys using magnesium-rich primers. J. Coat. Technol. Res. 2010, 7, 757-764.

52. King, A.D.; Scully, J.R. Sacrificial anode-based galvanic and barrier corrosion protection of 2024-T351 by a Mg-rich primer and development of test methods for remaining life assessment. Corrosion 2011, 67, 055004:1-055004:22.

53. Ravindran, N.; Chattopadhyay, D. K.; Zakula, A.; Battocchi, D.; Webster, D.C.; Bierwagen, G.P. Thermal stability of magnesium-rich primers based on glycidyl carbamate resins. Polym Degrad. Stab. 2010, 95, 1160-1166.

54. Hayes, S.; Brown, R.; Visser, P.; Adams, P.; Chapman, M. Magnesium rich primers and related developments for the replacement of chromium containing aerospace primers. In Proceedings of the 2011 Corrosion Conference, Houston, TX, USA, 13-17 March 2011; Available online: https://www.corrdefense.org/Spotlight/2011\%20Corrosion\%20Conference\%20Presentations/Mag nesium $\% 20$ rich $\% 20$ primers $\% 20$ and $\% 20$ related $\% 20$ developments $\% 20$ for $\% 20$ the $\% 20$ replacement $\% 20$ of $\% 20$ chromium\%20contraining\%20aerospace\%20primers.pdf (accessed on 30 April 2012).

55. Lu, X.; Zuo, Y.; Zhao, X.; Tang, Y.; Feng, X. The study of a Mg-rich epoxy primer for protection of AZ91D magnesium alloy. Corros. Sci. 2011, 53, 153-160. 
56. Bierwagen, G. The physical chemistry of organic coatings revisited-Viewing coatings as a materials scientist. J. Coat. Technol. Res. 2008, 5, 133-155.

57. Pathak, S.S.; Blanton, M.D.; Mendon, S.K.; Rawlins, J.W. Investigation on dual corrosion performance of magnesium-rich primer for aluminum alloys under salt spray test (ASTM B117) and natural exposure. Corros. Sci. 2010, 52, 1453-1463.

58. Strekalov, P.V. The atmospheric corrosion of metals by adsorbed polymolecular moisture layers. Prot. Met. 1998, 34, 501-519.

59. Smith, R.M.; Martell, A.E. Critical Stability Constants; Plenum Press: New York, NY, USA, 1973.

60. Jönsson, M.; Persson, D.; Thierry, D. Corrosion product formation during $\mathrm{NaCl}$ induced atmospheric corrosion of magnesium alloy AZ91D. Corros. Sci. 2007, 49, 1540-1558.

61. White, W.B. Thermodynamic equilibrium kinetics, activation barriers, and reaction mechanisms for chemical reactions in Karst Terrains. Environ. Geol. 1997, 30, 46-58.

62. Hosking, N.C.; Ström, M.A.; Shipway, P.H.; Rudd, C.D. Corrosion resistance of zinc-magnesium coated steel. Corros. Sci. 2007, 49, 3669-3695.

63. Duan, Z.; Sun, R. An improved model calculating $\mathrm{CO}_{2}$ solubility in pure water and aqueous $\mathrm{NaCl}$ solutions from 273 to $533 \mathrm{~K}$ and from 0 to 2000 bar. Chem. Geol. 2002, 193, 257-271.

64. Yao, H.B.; Li, Y.; Wee, A.T.S. An XPS investigation of the oxidation/corrosion of melt-spun Mg. Appl. Surf. Sci. 2000, 158, 112-119.

65. Portier, S.; Rochelle, C. Modelling $\mathrm{CO}_{2}$ solubility in pure water and NaCl-type waters from 0 to $300{ }^{\circ} \mathrm{C}$ and from 1 to 300 bar: Application to the Utsira Formation at Sleipner. Chem. Geol. 2005, 217, 187-199.

66. Henrist, C.; Mathieu, J.-P.; Vogels, C.; Rulmont, A.; Cloots, R. Morphological study of magnesium hydroxide nanoparticles precipitated in dilute aqueous solution. J. Cryst. Growth 2003, 249, 321-330.

67. Gao, Y.; Wang, H.; Su, Y.; Shen, Q.; Wang, D. Influence of magnesium source on the crystallization behaviors of magnesium hydroxide. J. Cryst. Growth 2008, 310, 3771-3778.

68. Wang, Y.; Li, Z.; Demopoulos, G.P. Controlled precipitation of nesquehonite $\left(\mathrm{MgCO}_{3} \cdot 3 \mathrm{H}_{2} \mathrm{O}\right)$ by the reaction of $\mathrm{MgCl}_{2}$ with $\left(\mathrm{NH}_{4}\right)_{2} \mathrm{CO}_{3}$. J. Cryst. Growth 2008, 310, 1220-1227.

69. Mitsuhashi, K.; Tagami, N.; Tanabe, K.; Ohkubo, T.; Sakai, H.; Koishi, M.; Abe, M. Synthesis of microtubes with a surface of "house of cards" structure via needlelike particles and control of their pore size. Langmuir 2005, 21, 3659-3663.

70. Pathak, S.S.; Blanton, M.D.; Mendon, S.K. School of Polymes and High Performance Materials, The University of Southern Mississippi Hattiesburg, MS, USA. Unpublished work, 2011.

71. Pathak, S.S.; Blanton, M.D.; Mendon, S.K.; Rawlins, J.W. Carbonation of Mg powder to enhance the corrosion resistance of Mg-rich primers. Corros. Sci. 2010, 52, 3782-3792.

72. Moore, D.M.; Reynolds, R.C. X-ray Diffraction and the Identification and Analysis of Clay Minerals; Oxford University Press: New York, NY, USA, 1989.

73. Khramov, A.N.; Balbyshev, V.N.; Kasten, L.S.; Mantz, R.A. Sol-gel coatings with phosphonate functionalities for surface modification of magnesium alloys. Thin Solid Films 2006, 514, 174-181. 
74. Turel, T.; Pathak, S.S.; Blanton, M.D.; Mendon, S.K.; Rawlins, J.W. Optimizing the Transformation of Magnesium Powder to Enhance its Corrosion Protection. In Proceedings of the 38th Annual International Waterborne, High-Solids, and Powder Coatings Symposium, New Orleans, LA, USA, 28 February-4 March 2011; pp. 430-437.

75. Maier, B.; Frankel, G.S. Behavior of magnesium-rich primers on AA2024-T3. Corrosion 2011, 67, 055001:1-055001:15.

76. Xu, H.; Battocchi, D.; Tallman, D.E.; Bierwagen, G.P. Use of magnesium alloys as pigments in magnesium-rich primers for protecting aluminum alloys. Corrosion 2009, 65, 318-325.

77. Bierwagen, G.; Brown, R.; Battocchi, D.; Hayes, S. Active metal-based corrosion protective coating systems for aircraft requiring no-chromate pretreatment. Prog. Org. Coat. 2010, 67, 195-208.

78. Wang, Y.-P.; Zhao, X.-H.; Lu, X.-Y.; Zuo, Y. Corrosion protection of ceria particle in Mg-rich primer on AZ91D magnesium alloy. Acta Phys. Chim. Sin. 2012, 28, 407-413.

79. Lu, X.; Zuo, Y.; Zhao, X.; Tang, Y. The improved performance of a Mg-rich epoxy coating on AZ91D magnesium alloy by silane pretreatment. Corros. Sci. 2012, 60, 165-172.

(C) 2012 by the authors; licensee MDPI, Basel, Switzerland. This article is an open access article distributed under the terms and conditions of the Creative Commons Attribution license (http://creativecommons.org/licenses/by/3.0/). 